\title{
Light-emitting MXene quantum dots
}

\author{
Anir S. Sharbirin' ${ }^{\dagger}$ Sophia Akhtar ${ }^{\dagger}$ and Jeongyong Kim*
}

\begin{abstract}
MXene $\left(M_{n+1} X_{n}\right)$ is an emerging class of layered two-dimensional (2D) materials, which are derived from their bulk-state MAX phase $\left(M_{n+1} A X_{n}\right.$, where $M$ : early transition metal, $A$ : group element 13 and 14, and $X$ : carbon and/or nitrogen). MXenes have found wide-ranging applications in energy storage devices, sensors, catalysis, etc. owing to their high electronic conductivity and wide range of optical absorption. However, the absence of semiconducting MXenes has limited their applications related to light emission. Research has shown that quantum dots (QDs) derived from MXene (MQDs) not only retain the properties of the parent MXene but also demonstrate significant improvement on light emission and quantum yield (QY). The optical properties and photoluminescence (PL) emission mechanisms of these light-emitting MQDs have not been comprehensively investigated. Recently, work on light-emitting MQDs has shown good progress, and MQDs exhibiting multi-color PL emission along with high QY have been fabricated. The synthesis methods also play a vital role in determining the light emission properties of these MQDs. This review provides an overview of light-emitting MQDs and their synthesis methods, optical properties, and applications in various optical, sensory, and imaging devices. The future prospects of light-emitting MQDs are also discussed to provide an insight that helps to further advance the progress on MQDs.
\end{abstract}

Keywords: MXene; quantum dots; light emission; MAX phase; 2D materials

Sharbirin AS, Akhtar S, Kim JY. Light-emitting MXene quantum dots. Opto-Electron Adv 4, 200077 (2021).

\section{Introduction}

Since the discovery of graphene by Novoselov et al. ${ }^{1,2}$, extensive research has been conducted on two-dimensional (2D) materials owing to their excellent properties. Over the years, several other 2D materials have been investigated, namely, hexagonal boron nitride $(\mathrm{hBN})^{3}$, transition metal dichalcogenides (TMDs) ${ }^{4}$, metal oxides, hydroxides $^{5}$ and their heterostructures ${ }^{6-8}$. In 2011, MXene, a new family of $2 \mathrm{D}$ materials that were produced by selective etching of the MAX phase (general formula of $M_{n+1} A X_{n}$, where $M$ is an early transition metal, $\mathrm{A}$ is main group elements 13 and 14 , and $\mathrm{X}$ is carbon and/or nitrogen) in liquid at room temperature, was discovered by Naquib et al. ${ }^{9}$. Until now, approximately 100 MAX phases have been fabricated and up to 30 MXenes have been reported, making them the largest group among the $2 \mathrm{D}$ family ${ }^{10}$.

MAX phases are layered ternary carbides, nitrides, or carbonitrides with a hexagonal crystal structure with space group $\mathrm{P}_{3} / \mathrm{mmc}$. Unlike other bulk $3 \mathrm{D}$ layered materials such as graphite and TMDs, which could be mechanically exfoliated with ease because of the weak van der Waals interactions that hold the structure together, the bonds between the layers in the MAX phase are too strong to be broken with similar means. However, by employing the relatively weaker M-A bonds compared to the M-X bonds, it is possible to selectively etch out the A layer by chemical means, leaving us with $M-X$ layers of MXenes with a general formula $\mathrm{M}_{n+1} \mathrm{X}_{n} \mathrm{~T}_{x}$, where $\mathrm{T}_{x}$ is the notation for a surface-terminating functional group $(\mathrm{O}, \mathrm{OH}, \mathrm{F}, \mathrm{H} \text {, etc. })^{10}$. Generally, aqueous solutions containing fluoride ions, such as aqueous hydrofluoric acid (HF), a mixture of lithium fluoride (LiF) or potassium fluoride (KF) with hydrochloric acid ( $\mathrm{HCl})$, or molten salts of fluoride, are used to selectively etch the A layers. After etching, the multilayer (ML)-MXenes are

Department of Energy Science, Sungkyunkwan University, Suwon 16419, Republic of Korea.

†These authors contributed equally to this work.

*Correspondence: JY Kim, Email: j.kim@skku.edu

Received: 3 November 2020; Accepted: 18 December 2020; Published: 25 March 2021 
immersed in dimethyl sulfoxide (DMSO), tetrabutyl ammonium hydroxide, alcohols, choline hydroxide, or nbutylamine for further delamination through sonication or centrifugation ${ }^{9-15}$. Compared to that obtained using single-element monolayer graphene, layered structures that contain more than one element provide large opportunities for functionalization to achieve varying properties. This is why MXene has been a promising candidate for a myriad of applications including energy storage devices, sensors, catalysis, water purification, transparent conductors, electromagnetic interference shielding, thermoelectrics, and plasmonics. One of the most widely studied applications of MXene is their use in energy storage devices mainly because of their high electronic conductivity ${ }^{9,10,14,16-22}$. Despite that there are many applications taking advantages of its various excellent properties, the application of MXenes in optoelectronic devices is still lacking. Although there are various theoretical reports on semiconducting MXenes, to the best of our knowledge, experimental work on these materials has not yet seen any success yet ${ }^{10,23}$. A breakthrough in the synthesis of light-emitting MXene-based materials is in demand.

Quantum dots derived from 2D materials (2D-QDs) have shown promising prospects for applications in nanomaterial-based devices. They not only inherit the merits of their 2D counterparts but also exhibit improved properties such as better dispersibility, higher chemical stability, easier functionalization, larger surface-tovolume ratio, and stronger photoluminescence (PL) after a size reduction (typically $<10 \mathrm{~nm}$ ) resulting from the strong quantum confinement and edge effect ${ }^{24}$. One of the widely known 2D-QDs that has benefitted from the quantum confinement and edge effect is graphene quantum dots (GQDs). When a few layers graphene is reduced to a size ranging from a few $\mathrm{nm}$ to $100 \mathrm{~nm}$, they show strong $\mathrm{PL}^{25}$. Other $2 \mathrm{D}-\mathrm{QD}$ s derived from TMDs and hBN have shown enhancement in PL, bandgap tunability, and functionality relative to those of their $2 \mathrm{D}$ counterparts ${ }^{26-28}$. By utilizing the same idea of reducing the dimensionality, it is possible to fabricate MXenebased 2D-QDs. The first reported work on MXene-derived QDs was in 2017 by Xue et al. ${ }^{29}$ by using $\mathrm{Ti}_{3} \mathrm{C}_{2}$ MXene as the precursor; blue PL emission with an absolute quantum yield (QY) of $10 \%$ was observed after the $\mathrm{Ti}_{3} \mathrm{C}_{2}$ MXene was broken down into a smaller size. As it retained the structure of its $2 \mathrm{D}$ counterpart in a smaller size, it is reasonable to use MQDs as the abbreviation for
MXene-derived quantum dots (MQDs). Like other 2DQDs, the emergence of MQDs has garnered the attention of researchers owing to their excellent properties, such as hydrophilicity, biocompatibility, functionalization, and more importantly, the PL property ${ }^{29-31}$.

More and more studies on MQDs are published in recent years; however, comprehensive reviews on MQDs are rarely found, and only one review has been published recently ${ }^{32}$. However, light-emitting properties of MQDs require special attention because MQDs can replace conventional luminescent QDs in photonic or bioapplications that require non-toxic and biocompatible materials. In this review, we provide a general overview of the synthesis methods, physical, chemical, and structural properties, and the applications of MQDs with a focus on their light-emitting aspects and also provide a perspective for future opportunities and challenges of light-emitting MQDs for photonic and bio-applications.

\section{Synthesis of MAX phase and MXene}

Even though there are numerous techniques and methods available to synthesize MQDs, the basis of synthesizing light-emitting MQDs is the same which is reducing the size of MXene (typically $<10 \mathrm{~nm}$ ) to induce bandgap expansion by quantum confinement effect ${ }^{29,30,33-38}$. Thus, any method could be used to synthesize light emitting MQDs as long there is a size reduction while maintaining the structure of the precursor (MXene). However, the properties of MQDs are heavily dependent on the parent precursors used for MQD synthesis, which are the MAX phase and MXene. Only several methods of specific synthesis conditions and parent MXene precursors lead to the synthesis of light-emitting MQDs with desired properties. Various $\mathrm{M}_{n+1} \mathrm{AX}_{n}$ phases have been obtained by selecting different $n$ values and/or different $\mathrm{M}, \mathrm{A}$, or $\mathrm{X}$ elements. The strong $\mathrm{M}-\mathrm{X}$ covalent bond and $\mathrm{M}-\mathrm{A}$ metallic bond of the MAX phase cannot be broken by mechanical exfoliation. To prepare MXenes from the MAX phase, strong etchants such as lithium fluoride-hydrochloric acid mixtures ( $\mathrm{LiF}-\mathrm{HCl}$ ), ammonium hydrogen bifluoride $\left(\mathrm{NH}_{4} \mathrm{HF}_{2}\right)$, and $\mathrm{HF}$ are employed ${ }^{9-11,13,39,40}$. In this review, we limit our review to MQDs derived from $\mathrm{Ti}_{3} \mathrm{C}_{2}, \mathrm{~V}_{2} \mathrm{C}$, and $\mathrm{Nb}_{2} \mathrm{C}$ MXenes. These MQDs exhibit great light-emitting properties and high photoluminescence QY (PLQY).

\section{Synthesis of MAX phase}

The $\mathrm{Ti}_{3} \mathrm{AlC}_{2} \mathrm{MAX}$ phase was first discovered by Pietzka et al. ${ }^{41}$ in 1994 while investigating the $\mathrm{Ti}-\mathrm{Al}-\mathrm{C}$ ternary 
phase diagram. The compound $\mathrm{Ti}_{3} \mathrm{AlC}_{2}$ gained increasing attention owing to its lightweight and superior properties compared to other layered ternaries. A few methods used to synthesize the $\mathrm{Ti}_{3} \mathrm{AlC}_{2} \mathrm{MAX}$ phase, as well as other types, have been discussed below. The hot isostatic pressing (HIP) method ${ }^{42}$ is used to densify the sintered components and enhance the interfacial bonding. HIP involves the simultaneous application of elevated temperature and high pressure in a sealed or an enclosed vessel. Usually, an inert gas is used to apply the pressure, as suggested by the name of isostatic. HIP is mainly concerned with the removal of pores that are induced during calcination from gas evolution, packing of the particles of powder, agglomeration of vacancies, and interdiffusion during bonding of dissimilar materials. Under high temperature and pressure, the internal defects or pore collapse and precursors are densified ${ }^{42}$. The bulk polycrystalline $\mathrm{Ti}_{3} \mathrm{AlC}_{2} \mathrm{MAX}$ phase was first synthesized by Tzenov and Barsoum ${ }^{43}$. A mixture of Ti, graphite, and $\mathrm{Al}_{4} \mathrm{C}_{3}$ precursors was ball-milled, followed by HIP. The samples synthesized by HIP were observed to be single phase and fully dense with a grain size of nearly $25 \mu \mathrm{m}$. $\mathrm{Ti}_{3} \mathrm{AlC}_{2}$ is isostructural and possesses the merits of both ceramics and metals: it exhibits high modulus, high strength at high temperatures, and low thermal expansion coefficient ${ }^{43}$. Wang and $\mathrm{Zhou}^{44}$ also fabricated $\mathrm{Ti}_{3} \mathrm{AlC}_{2}$ by solid-liquid reaction synthesis and simultaneous in situ hot pressing process.

The synthesis of the MAX phase is usually performed at very high temperatures. Gogotsi et al. ${ }^{45}$ synthesized $\mathrm{Ti}_{3} \mathrm{AlC}_{2}$ by using powder precursors of $\mathrm{Ti}, \mathrm{Al}$, and graphite at $1650{ }^{\circ} \mathrm{C}$ following a high-temperature synthesis method. Barosum et al. ${ }^{46}$ synthesized $\mathrm{V}_{2} \mathrm{AlC}$ by ball milling of powders of $\mathrm{V}, \mathrm{Al}$, and $\mathrm{C}$, followed by calcination at a high temperature of $1500{ }^{\circ} \mathrm{C}$. Afterwards, the synthesized MAX phase was sieved, and a 400 mesh powder was used for MXene synthesis.

$\mathrm{The} \mathrm{Nb}_{2} \mathrm{AlC}$ phase was synthesized for the first time in 1980 by Schuster and Nowotny ${ }^{47,48}$ while investigating phase equilibrium in the $\mathrm{Nb}-\mathrm{Al}-\mathrm{C}$ system. $\mathrm{Nb}_{2} \mathrm{AlC}$ was prepared by arc melting and annealing. Barsoum et al. ${ }^{49}$ used reactive HIP to fabricate bulk $\mathrm{Nb}_{2} \mathrm{AlC}$ from the precursors including $\mathrm{Nb}, \mathrm{C}$, and $\mathrm{Al}_{4} \mathrm{C}_{3}$. Zhang et al. ${ }^{50} \mathrm{em}$ ployed reactive hot pressing to synthesize $\mathrm{Nb}_{2} \mathrm{AlC}$ from $\mathrm{NbC}, \mathrm{Nb}$, and $\mathrm{Al}$ precursor powders. Kovalev et al. ${ }^{48}$ synthesized $\mathrm{Nb}_{2} \mathrm{AlC}$ by using the self-propagating high-temperature synthesis method. They suggested that this method is highly productive and requires no complex equipment. The initial precursors were $\mathrm{Nb}$ (IV) oxide, $\mathrm{Al}$, and $\mathrm{C}$.

Zhou et al. ${ }^{51}$ used the spark plasma sintering technique to synthesize $\mathrm{Nb}_{2} \mathrm{AlC}$. The powdered precursors with a molar ratio of $\mathrm{Nb}: \mathrm{Al}: \mathrm{NbC}=2: 1.2: 1$ were employed and ethanol was used as a mixing medium. Afterwards, the obtained powder was compacted under 20 MPa pressure. Finally, sintering was done in a spark plasma sintering system at $1450{ }^{\circ} \mathrm{C}$ at a heating rate of $100^{\circ} \mathrm{C} / \mathrm{min}$ under $30 \mathrm{MPa}$. They concluded that the obtained $\mathrm{Nb}_{2} \mathrm{AlC}$ exhibited good electrical, thermal, and mechanical properties. Barosum et al. ${ }^{46}$ synthesized $\mathrm{Nb}_{2} \mathrm{AlC}$ by mixing $\mathrm{Nb}, \mathrm{Al}$, and $\mathrm{C}$.

\section{Synthesis of MXene}

For the synthesis of MXene, the MAX phase is etched using $10-50 \mathrm{wt} . \% \mathrm{HF}$ as reported in most synthesis proto$\operatorname{cols}^{9,40,52}$. The HF etching method includes the gradual addition of the MAX phase in the etchant while stirring at room temperature. The gradual addition of the MAX phase tends to minimize the bubbling, which is caused by the exothermic nature of this reaction. $\mathrm{Ti}_{3} \mathrm{C}_{2}$ MXene was prepared by Xue et al. ${ }^{29}$ by selectively etching the " $\mathrm{A}$ " layer in the $\mathrm{Ti}_{3} \mathrm{AlC}_{2} \mathrm{MAX}$ phase with $48 \% \mathrm{HF}$. Alhabeb et al. ${ }^{52}$ prepared $\mathrm{Ti}_{3} \mathrm{C}_{2} \mathrm{~T}_{x}$ by etching $\mathrm{Al}$ from the $\mathrm{Ti}_{3} \mathrm{AlC}_{2}$ MAX phase in the presence of HF. By using this etching process, ML-MXene powders are obtained with 2D layers held by van der Waals forces and hydrogen bonds ${ }^{52}$. After etching, the residual acid is removed by repeatedly washing the powders. Once the $\mathrm{pH}$ is neutral, MXene is obtained and filtered out by vacuum filtration. The two layers of exposed Ti atoms in the unit cell require passivation of dangling bonds ${ }^{53}$. As HF contains abundant hydroxyl and fluorine anions, the surface of the MXene nanosheets is terminated with $-\mathrm{F},-\mathrm{O}$, and/or $\mathrm{OH}$ functional groups after the etching of the " $\mathrm{A}$ " layer from the MAX phase ${ }^{54}$. To etch out Al to make MXene, Naguib et al. ${ }^{46}$ immersed $\mathrm{V}_{2} \mathrm{AlC}$ and $\mathrm{Nb}_{2} \mathrm{AlC}$ powders in $50 \%$ and $55 \%$ concentrated HF solutions, respectively, for different times along with continuous stirring at room temperature. After the HF treatment, the resulting suspensions were washed several times using deionized water and centrifuged to separate the settled powders from the supernatants. The settled powders were removed from the vials using ethanol and dried.

Owing to the hazardous nature of HF, a fluoride salt was employed to make a mild etchant. A mild etchant 
solution was prepared by mixing $\mathrm{HCl}$ and $\mathrm{LiF}$ under stirring at room temperature. This resulted in a clear $\mathrm{HF}$ solution with a low concentration, normally $3 \%-5 \%{ }^{13}$. The $\mathrm{Ti}_{3} \mathrm{AlC}_{2}$ powder was topo-chemically converted into MXene by Shuck et al. ${ }^{45}$. They reported the preparation of an etchant by mixing $1.6 \mathrm{~g}$ of $\mathrm{LiF}$ and $15 \mathrm{~mL}$ of $\mathrm{HCl}$ (37 wt.\%) in $5 \mathrm{~mL}$ of deionized water. Afterwards, the as-synthesized $\mathrm{Ti}_{3} \mathrm{AlC}_{2}$ powder was added gradually to a premixed etchant solution and stirred. After washing and centrifuging, the colloidal solution of delaminated $\mathrm{Ti}_{3} \mathrm{C}_{2} \mathrm{~T}_{x}$ was obtained. The ratio of $\mathrm{LiF}$ to $\mathrm{HCl}$ in the etchant defines the quality and lateral size of MXene nanosheets. Large flakes with clean surfaces displayed higher electrical conductivity owing to the fewer defects on nanosheets compared with those on ones prepared by using $\mathrm{HF}$ as the etchant ${ }^{55}$.

\section{Synthesis of MXene quantum dots}

Multiple methods and approaches have been used to prepare MQDs. These methods can be categorized into topdown and bottom-up approaches ${ }^{56}$. Either of the methods can be used depending on the desired size, morphology, structure, and functionalization ${ }^{56-57}$.

Top-down approaches usually involve the cleavage of bulk MXene precursors by employing physical ${ }^{58}$, chemic$\mathrm{al}^{26}$ or electrochemical ${ }^{59}$ methods. The top-down approach can be used for large-scale production, and the raw materials required are found abundantly in nature. It also has some limitations, such as low production yield ${ }^{56}$ and requirement of post-synthesis treatments ${ }^{60}$. As shown in Fig. 1, the top-down synthesis mainly includes

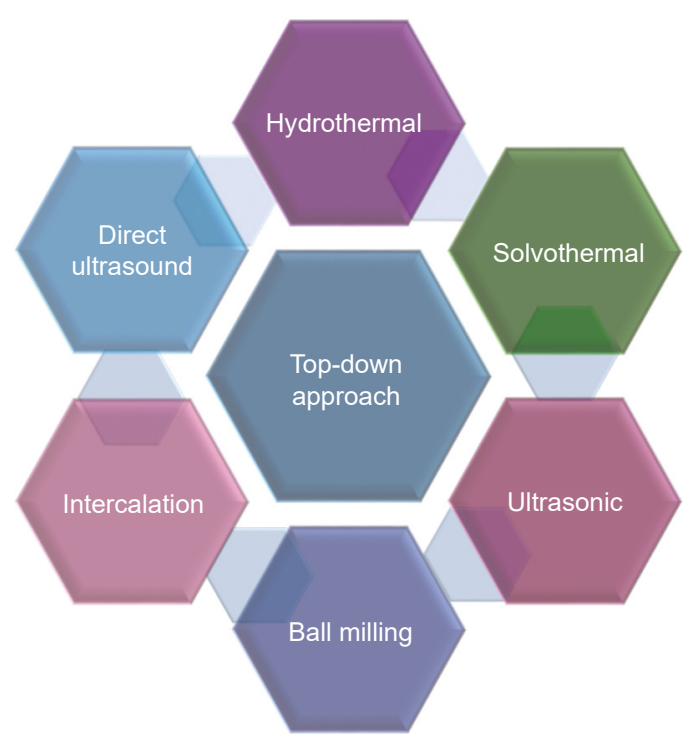

Fig. 1 | Top-down approaches for MQD synthesis. hydrothermal $^{61}$, solvothermal ${ }^{62}$, ultrasonic ${ }^{63,64}$, ball milling ${ }^{34,64}$ and intercalation methods ${ }^{65}$.

\section{Hydrothermal/solvothermal method}

Hydrothermal/solvothermal is the most common approach that uses MXene as a precursor to synthesize MQDs ${ }^{29,30,66}$. The synthesis of MQDs via hydrothermal methods is a two-step crystallization process: crystal nucleation and subsequent growth. By controlling processing variables such as temperature, $\mathrm{pH}$, reactant concentrations, and additives, desired particle sizes and morphologies of the final products can be obtained ${ }^{67}$. Xue et al. ${ }^{29}$ synthesized $\mathrm{Ti}_{3} \mathrm{C}_{2}$ MXene by selectively etching the A layer in the $\mathrm{Ti}_{3} \mathrm{AlC}_{2}$ MAX phase with $48 \% \mathrm{HF}$ (Fig. 2(a)). The MQDs were prepared through a facile hydrothermal method by cutting bulk layered $\mathrm{Ti}_{3} \mathrm{C}_{2}$ MXene. Colloidal MQDs with different morphologies were obtained by changing the reaction temperature. The chemical structure and PL mechanism of the MQDs prepared at different temperatures were investigated. Blue fluorescence was obtained with a QY of $10 \%$. Cao et al. ${ }^{68}$ employed a hydrothermal method to synthesize $\mathrm{V}_{2} \mathrm{C}$ QDs by using a $\mathrm{V}_{2} \mathrm{C}$ nanosheet precursor (Fig. 2(b)). The average thickness of $\mathrm{V}_{2} \mathrm{C}$ QDs was $0.8 \mathrm{~nm}$, indicating that the $\mathrm{V}_{2} \mathrm{C}$ QDs were single-layer atomic crystals.

The solvothermal synthesis method employs organic solvents as the reaction medium instead of water; ethanol, DMSO, and dimethylformamide (DMF) are commonly used solvents. The solvothermal method is advantageous over the hydrothermal synthesis in that the morphology ${ }^{69}$, size $^{70}$ and dispersion ${ }^{71}$ of MQDs could be easily controlled. Feng et al. ${ }^{62}$ prepared nitrogen-doped $\mathrm{Ti}_{3} \mathrm{C}_{2}$ MQDs with an amine-assisted facile solvothermal method. They exfoliated the purchased MXene by using a solvent-aided sonication method to achieve few-layer MXene. N,N-DMF and diethylenetriamine were used as solvents for the exfoliated few-layered MXene, which resulted in nitrogen-doped $\mathrm{Ti}_{3} \mathrm{C}_{2}$ MQDs with a size and thickness of $6.2 \mathrm{~nm}$ and $1 \mathrm{~nm}$, respectively. Nitrogen doping in N-MQDs reduced the size and size distribution of the MQDs. The absolute fluorescence QY of nitrogen-doped MQDs was $16.9 \%{ }^{62}$. The solvothermal route was employed by $\mathrm{Xu}$ et $\mathrm{al} .^{70}$ to prepare three types of $\mathrm{Ti}_{3} \mathrm{C}_{2}$ MQDs using three solvents: ethanol, DMF, and DMSO (Fig. 2(c)). All supernatants of the MQDs demonstrated good stability, dispersion, and different colors. The atomic thickness of the $\mathrm{Ti}_{3} \mathrm{C}_{2}$ MQDs was 

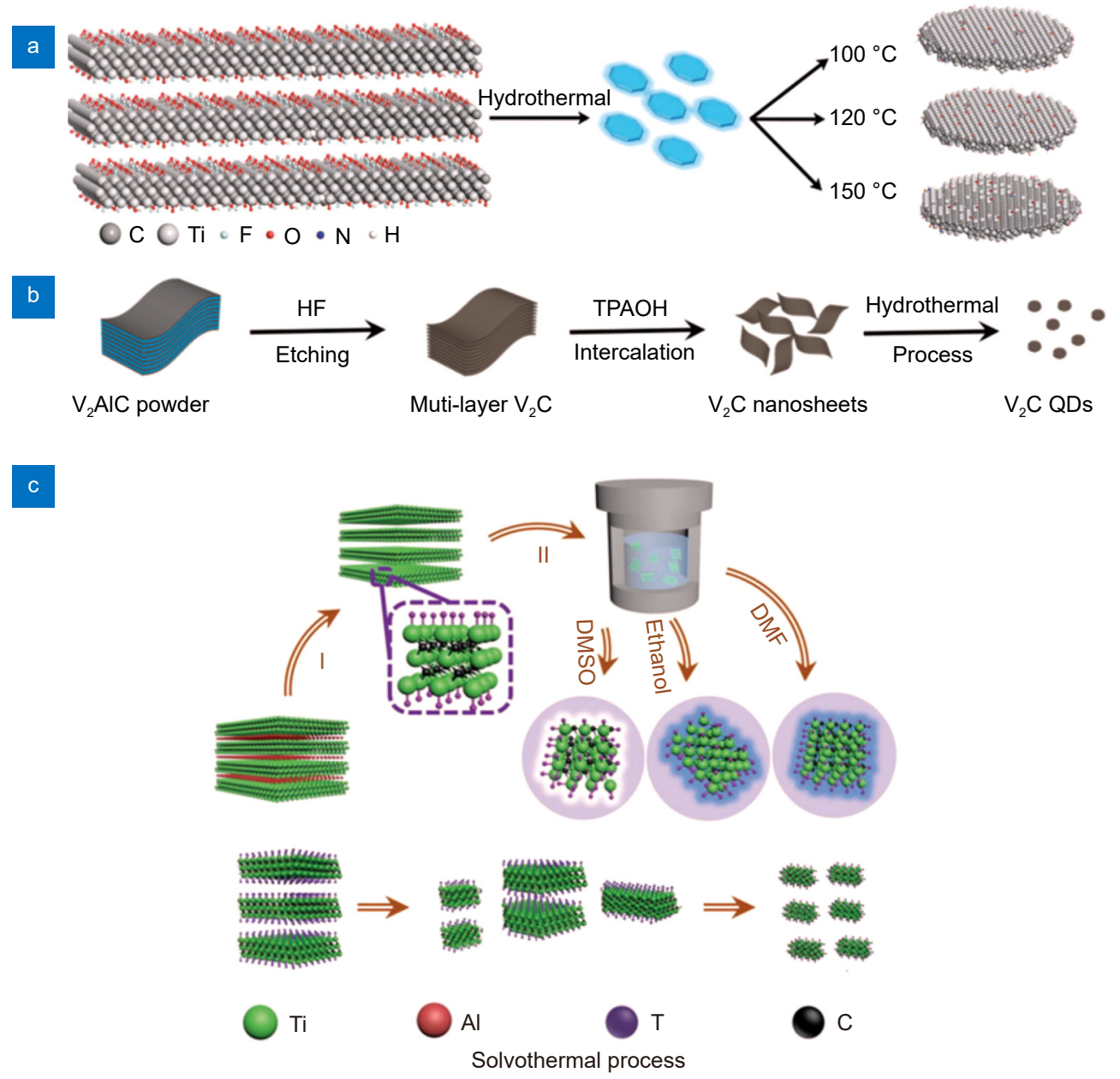

Fig. 2 | Hydrothermal and solvothermal synthesis processes. The figures were reproduced with permission from: (a) ref. ${ }^{29}$, Copyright 2017 , John Wiley and Sons; (b) ref. ${ }^{68}$, Copyright 2019, Elsevier; (c) ref. ${ }^{70}$, Copyright 2018, John Wiley and Sons.

$1.0-2.5 \mathrm{~nm}$, indicating the presence of few layers. The size of MQDs was dependent on the solvent they used, and the sizes of $\mathrm{Ti}_{3} \mathrm{C}_{2}$ MQDs in ethanol, DMF, and DMSO were $1.8 \pm 0.1,2.5 \pm 0.2$, and $3.3 \pm 0.2 \mathrm{~nm}$, respectively ${ }^{70}$. The variation in size could be attributed to the co-action of oxidation degree ${ }^{72}$, boiling point, and polarity of solvents ${ }^{73}$.

\section{Hydrothermal/solvothermal-ultrasound method}

Combining ultrasonication with the solvothermal/hydrothermal method is an efficient strategy to synthesize MQDs rather than using solvothermal or hydrothermal methods alone $\mathrm{e}^{36,37,74,75}$. Ultrasonication can cause shockwaves and acoustic cavitation in certain solvents. It is also useful to suppress the oxidation of MXene and accelerate the fragmentation of MXene sheets to MQDs ${ }^{76,77}$. Usually, probe and bath ultrasonic methods are used for the synthesis of MQDs. MQDs prepared by probe ultrasonication are more dispersed than those prepared using bath ultrasonication ${ }^{78}$. The ultrasonic treatment of a liquid affects the intensity of mixing and heating of bulk liquid, as well as the concentration of energy in microscopic hot spots which are required to produce high-energy chemical reactions. Both the physical and chemical effects of ultrasound have been demonstrated in the production of nanostructured materials ${ }^{79}$. Li et al. ${ }^{66}$ prepared $\mathrm{Ti}_{3} \mathrm{C}_{2}$ MQDs by using the ultrasound-hydrothermal method, as shown in Fig. 3. The $\mathrm{Ti}_{3} \mathrm{C}_{2}$ sheets were dispersed by tip sonication and bath sonication, and then, the dispersion was treated hydrothermally overnight. Zhou et al. ${ }^{75}$ used the solvothermal-ultrasound method to synthesize $\mathrm{Ti}_{3} \mathrm{C}_{2}$-derived graphene QDs (GQDs). A product yield of 32.6\% was obtained for GQDs, which is very high. Huang et al. ${ }^{37}$ synthesized $\mathrm{V}_{2} \mathrm{C}$ MQDs by employing a hydrothermal method, followed by ultrasound treatment in ammonium hydroxide. Blue fluorescence was obtained with a QY of $15.88 \%$. 


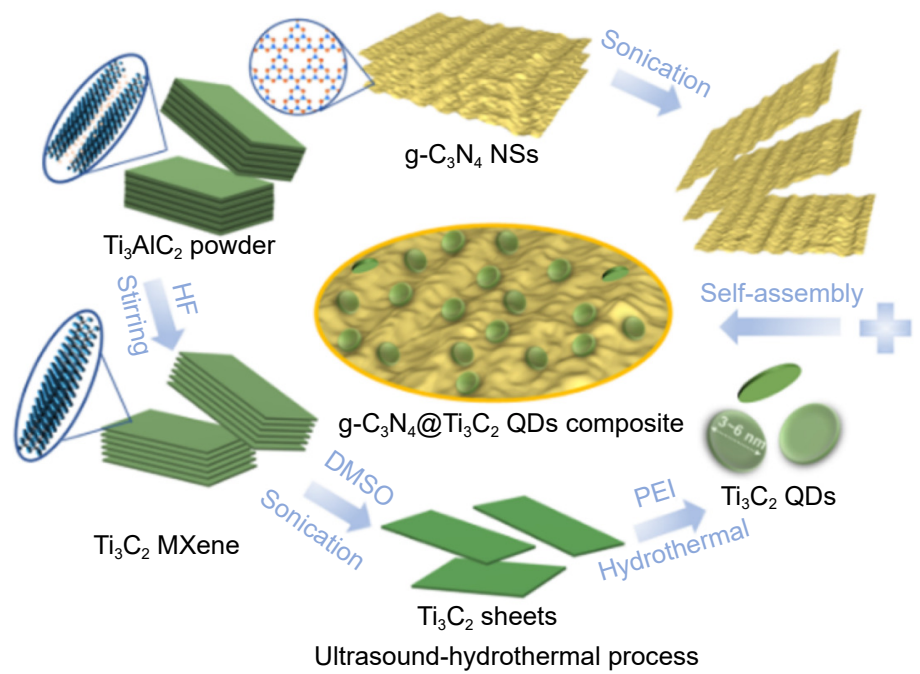

Fig. 3 | Solvothermal/hydrothermal-ultrasound synthesis process. The figure was reproduced from: ref. ${ }^{66}$, Copyright 2019, American Chemical Society.

\section{Ultrasonic, ball milling, and intercalation methods}

Several other top-down approaches to prepare MQDs include intercalation ${ }^{65}$, ball milling ${ }^{34,64}$ and direct ultrasound. A two-step ultrasound approach was used by $\mathrm{Yu}$ et al. ${ }^{63}$ to synthesize ultra-small $\mathrm{Ti}_{3} \mathrm{C}_{2}$ MQDs. The probe sonication breaks down the bulk MXene, which increases the surface area, thereby providing more surfaces and edges available for reaction. $\mathrm{Nb}_{2} \mathrm{C}$ QDs were synthesized by Yang et al..$^{38}$ by employing a pulsed ultrasound method, followed by physicochemical exfoliation in tetrapropylammonium hydroxide (TPAOH). Wang et al. ${ }^{33}$ synthesized $\mathrm{Ti}_{3} \mathrm{C}_{2}$ MQDs by employing an intercalation-ultrasound method, followed by delamination of MXene layers, as shown in Fig. 4(a). MXene nanosheets were reacted with $25 \%$ tetramethylammonium hydroxide (TMAOH), followed by treatment in an ultrasonic bath to obtain MQDs. Blue fluorescence was observed for ultra-small $\mathrm{Ti}_{3} \mathrm{C}_{2}$ sheets with a high QY of $8.9 \%$. Additionally, $\mathrm{Mo}_{2} \mathrm{C}$ MQDs were synthesized by Dai et al. ${ }^{80}$ using $\mathrm{Mo}_{2} \mathrm{C}$ powder as the starting material by following a one-step bath ultrasonic treatment, as shown in Fig. 4(b). The synthesized MQDs had a diameter of $\sim 6 \mathrm{~nm}$, were highly stable and biocompatible, and possessed low cytotoxicity. The ball milling technique (Fig. 4(c)) was employed by Zhang et al. ${ }^{81}$ to synthesize $\mathrm{Ti}_{3} \mathrm{C}_{2}$ MQDs with different sizes. They ball-milled $\mathrm{Ti}_{3} \mathrm{C}_{2}$ MXene with multiple elements in an inert environment. However, they concluded that this method is more suitable for the synthesis of composite materials.

Top-down synthesis methods are efficient for obtaining MQDs, but they possess drawbacks such as long synthesis time and low yield, as discussed above. Thus, ad- vanced methods such as microwave synthesis or electrochemical synthesis have been used. These methods exhibit good reproducibility, involve simple operations, and are cost-effective and thus yield good results.

MQDs were also synthesized using the following bottom-up synthesis approach. The bottom-up method uses organic or inorganic molecular materials as precursors, which enables the precise manipulation of size distribution, morphology, or surface functionalization ${ }^{56-57}$. Until now, there have been no reports of light-emitting MQDs synthesized using bottom-up methods. However, it is worthwhile to discuss the utilization of the bottom-up method for the fabrication of MQDs so that we could increase the possibility of finding new synthesis methods.

\section{Molten salt synthesis}

In the molten salt synthesis method, a salt with a low melting point is added to the reactants. After the salt addition, the precursors are heated above the melting point of the salt. This causes the salt to melt and act as a solvent. Cheng et al. ${ }^{82}$ synthesized a $\mathrm{Mo}_{2} \mathrm{C}$ QDs/carbon nanosheet $\left(\mathrm{Mo}_{2} \mathrm{C} / \mathrm{C}\right)$ composite by using a molten salt synthesis approach (Fig. 5(a)). Molybdenum acetylacetonate, sucrose, and $\mathrm{NaCl}$ were used as parent precursors for the synthesis of MQDs. The characterization of $\mathrm{Mo}_{2} \mathrm{C}$ MQDs revealed a size of 2-3 $\mathrm{nm}$ and interplanar spacing of $2.37 \AA$ ( $\left.1 \AA=10^{-10} \mathrm{~m}\right)$, which was well corresponding with $\mathrm{Mo}_{2} \mathrm{C}$ (002) plane.

\section{Pyrolysis method}

Wang et al. ${ }^{83}$ synthesized $\mathrm{Mo}_{2} \mathrm{C}$ QDs/carbon polyhedron 


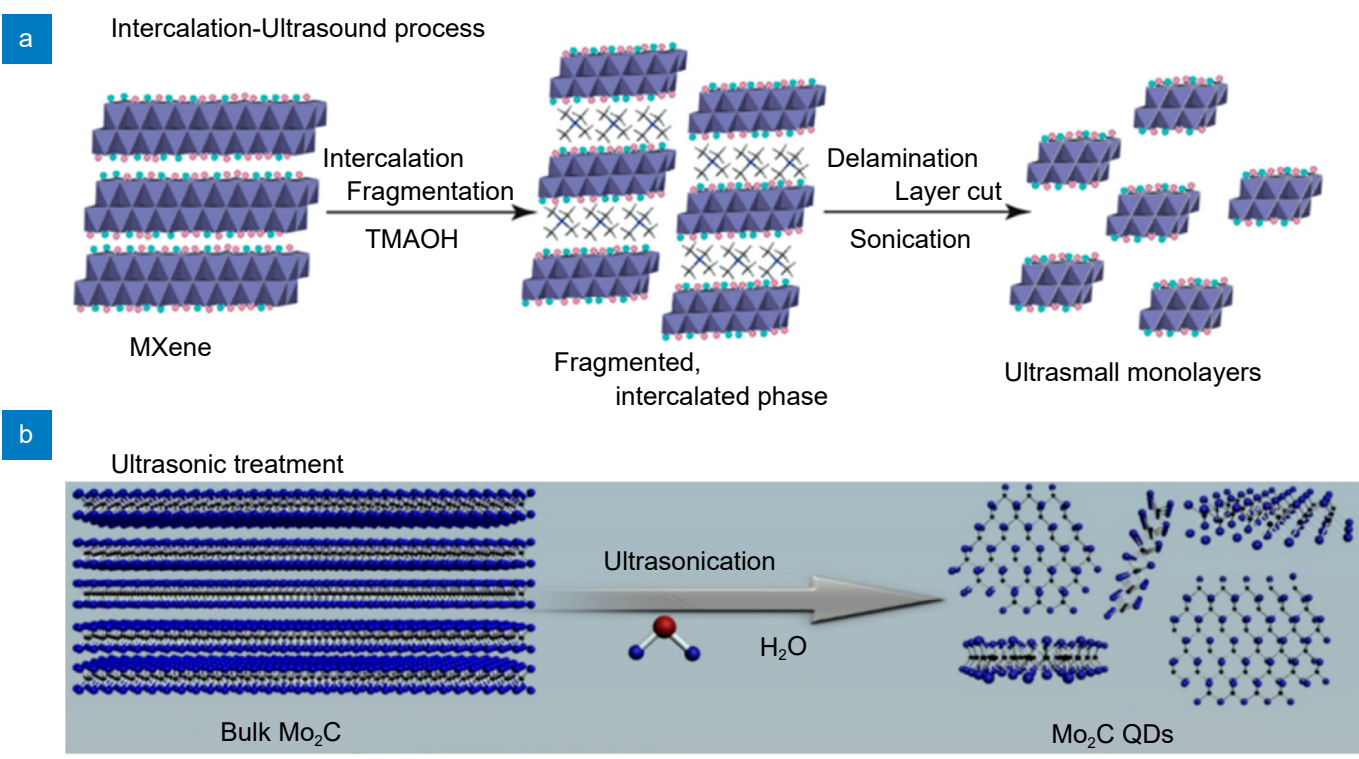

Ball-Milling

$\mathrm{Ti}_{3} \mathrm{AlC}_{2}$

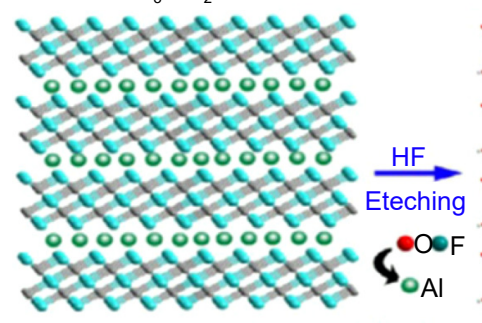

OTi OC OO O CH P OAl
$\mathrm{Ti}_{3} \mathrm{C}_{2} \mathrm{~T}_{x}$

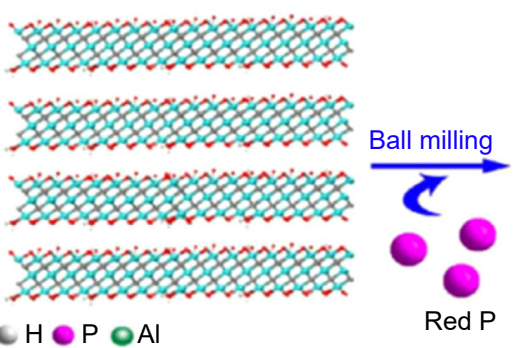

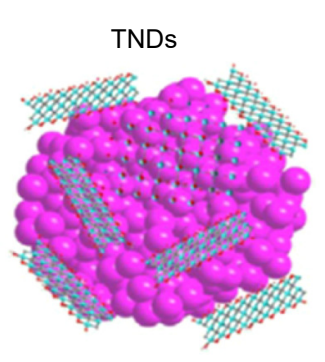

Fig. 4 | Ultrasonic, ball milling, and intercalation synthesis methods. The figures were reproduced from: (a) ref. ${ }^{33}$, Copyright 2017, American Chemical Society; (b) ref. ${ }^{80}$, Copyright 2018, under a Creative Commons Attribution lisence; (c) ref..$^{81}$, Copyright 2018, Wiley-VCH.

composites by employing a pyrolysis method (Fig. 5(b)). Molybdic acid, zinc acetate, and 2-methylimidazole were used as precursors. $\mathrm{Mo}_{2} \mathrm{C}$ QDs exhibited an average diameter of $4.5 \mathrm{~nm}$. High-resolution transmission electron microscopy (HRTEM) imaging revealed that lattice fringes of $0.24 \mathrm{~nm}$ were well associated with the (111) plane of cubic $\mathrm{Mo}_{2} \mathrm{C}$. The bottom-up approach to synthesize MQDs is relatively simple compared with the top-down approach.

Currently, only top-down method has successfully yielded light-emitting MQDs. This may be due to the precursor selection for MQDs synthesis. $\mathrm{Mo}_{2} \mathrm{C}$ is known to have metallic electronic properties ${ }^{84}$ compared with other MXene such as $\mathrm{Ti}_{3} \mathrm{C}_{2}$ that is semi-metallic ${ }^{9}$. Due to the limitation of precursor selection, there is no observation of light-emitting MQDs yielding from bottom-up method so far ${ }^{32,82,83}$. The following Table 1 lists few lightemitting MQDs along with their synthesis method and the PLQY achieved.

\section{Light-emitting properties of MXene quantum dots}

PL is the emission of light from matter after the absorption of incident light or photons. The reaction mechanism behind PL from MQDs is not yet completely clear. Factors such as functional groups, surface defects, degree of passivation, and quantum confinement have previously been proposed to be the origin of $\mathrm{PL}$ in MQDs ${ }^{85}$ similar to the case of graphene and carbon $\mathrm{QDs}^{86-88}$. However, the PL reaction mechanism is still controversial and further studies are required for better understanding ${ }^{86-88}$. Following are the discussions about the PL behavior in MQDs.

\section{Origin of photoluminescence, absorption, and quantum yield}

It was theoretically (density functional theory, DFT) predicted that $\mathrm{Ti}_{3} \mathrm{C}_{2}$ MXene has a small bandgap of $\sim 0.1 \mathrm{eV}$, which could be further expanded by quantum effects, 


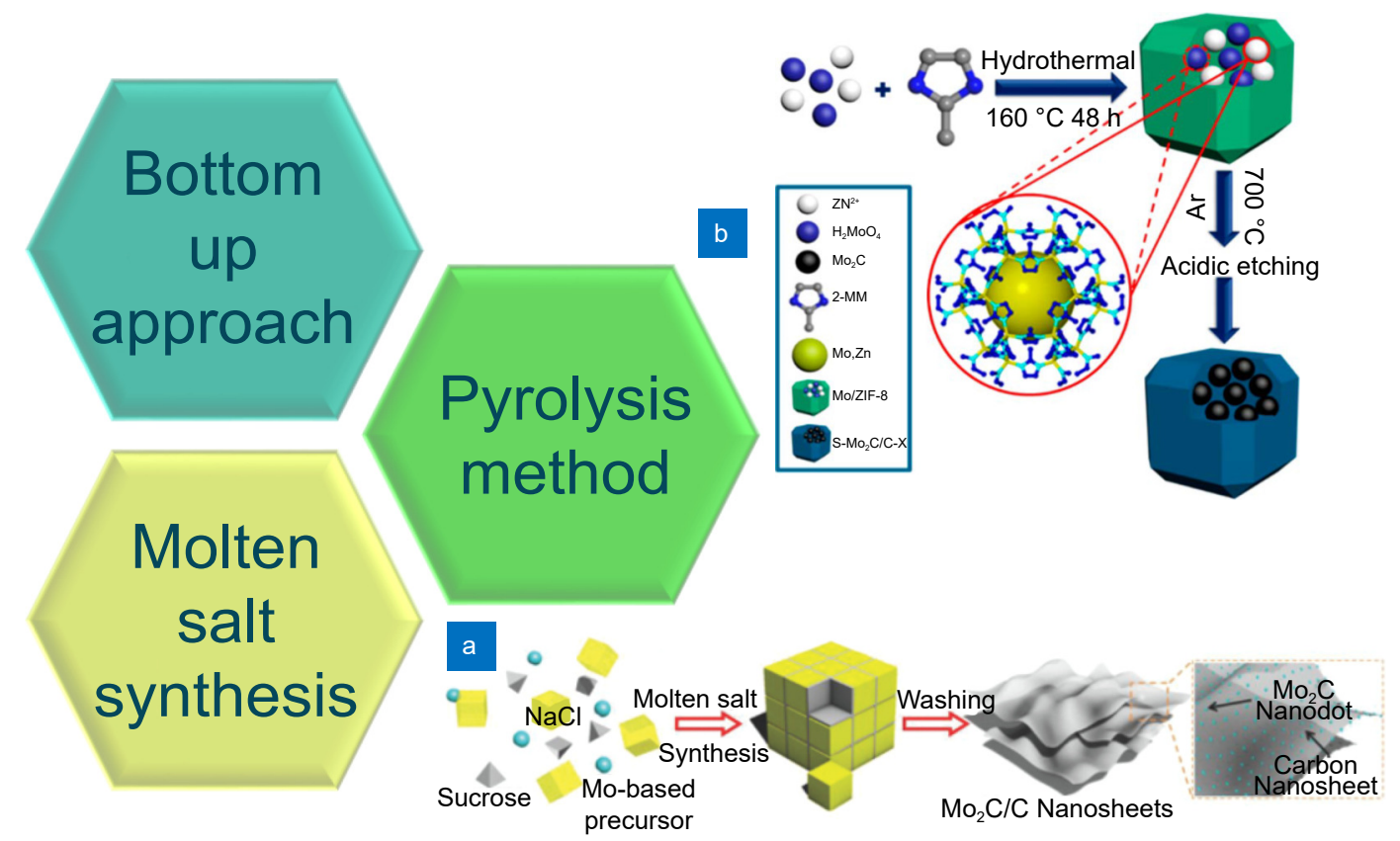

Fig. 5 | Types of bottom-up synthesis processes. The figures were reproduced from: (a) ref. ${ }^{82}$. Copyright 2018, John Wiley and Sons; (b) ref. ${ }^{83}$, Copyright 2018, American Chemical Society.

Table 1 | Current progress on MQDs exhibiting photoluminescence

\begin{tabular}{|c|c|c|c|}
\hline MQDs & Synthesis methods & PLQY & Ref (Year) \\
\hline \multirow{6}{*}{$\mathrm{Ti}_{3} \mathrm{C}_{2}$} & Hydrothermal $(\mathrm{pH}=9): 100^{\circ} \mathrm{C}, 120^{\circ} \mathrm{C}, 150^{\circ} \mathrm{C}, 6 \mathrm{~h}$ & $10 \%$ (Blue) & ref. ${ }^{29}(2017)$ \\
\hline & Ultrasound (25\% TMAOH): $24 \mathrm{~h}$ & $8.9 \%$ (Blue) & ref. ${ }^{33}(2017)$ \\
\hline & Hydrothermal $\left(\mathrm{pH}=7, \mathrm{~N}\right.$-doped): $160^{\circ} \mathrm{C}, 12 \mathrm{~h}$ & $18.7 \%$ (Blue) & ref. ${ }^{34}(2018)$ \\
\hline & Acid Reflux: $100^{\circ} \mathrm{C}, 12 \mathrm{~h}$, Hydrothermal: $\mathrm{pH}=7, \mathrm{~N}-, \mathrm{P}$-doped $120^{\circ} \mathrm{C}, 12 \mathrm{~h}$ & $20.1 \%$ (Green) & ref. $^{35}(2019)$ \\
\hline & Ultrasound: $600 \mathrm{~W}, 6 \mathrm{~h}$, Solvothermal: $80^{\circ} \mathrm{C}, 48 \mathrm{~h}$ & $9.36 \%$ (White) & ref. ${ }^{36}(2019)$ \\
\hline & Hydrothermal (pH = 7, S-,N-, SN-doped); $150^{\circ} \mathrm{C}, 12 \mathrm{~h}$ & $28.12 \%$ (Blue), $8.33 \%$ (Yellow), $7.78 \%$ (Orange) & ref. ${ }^{30}(2019)$ \\
\hline $\mathrm{V}_{2} \mathrm{C}$ & Ultrasound: $1 \mathrm{~h}$, Hydrothermal (alkaline): $120^{\circ} \mathrm{C}, 6 \mathrm{~h}$ & $15.88 \%$ (Blue) & ref. ${ }^{37}(2019)$ \\
\hline $\mathrm{Nb}_{2} \mathrm{C}$ & Ultrasound ( $\mathrm{pH}=6,60 \mathrm{ml}$ TPAOH): $10 \mathrm{~h}$ & 8.4\% (Bluish Green) & ref. $^{38}(2020)$ \\
\hline
\end{tabular}

and light emission can be induced ${ }^{11,89}$. Xue et al. ${ }^{29}$ explained the chemical structure and PL of $\mathrm{Ti}_{3} \mathrm{C}_{2}$ MQDs prepared by the hydrothermal method (Fig. 6(a)) at various temperatures. They adjusted the temperature to obtain $\mathrm{Ti}_{3} \mathrm{C}_{2}$ MQDs with different concentrations of $\mathrm{Ti}$. The $\mathrm{Ti}_{3} \mathrm{C}_{2} \mathrm{MQDs}$ prepared at $100{ }^{\circ} \mathrm{C}, 120^{\circ} \mathrm{C}$, and $150{ }^{\circ} \mathrm{C}$ were named as MQD-100, MQD-120, and MQD-150, respectively. MQD-100 displayed a pristine structure of MXene, and the PL was proposed to arise from the MXene material itself (Fig. 6(e, h)). MQD-120 displayed a hybrid structure with $\mathrm{TiO}_{2}$ at the surface and $\mathrm{C}-\mathrm{Ti}$ in the core (Fig. 6(f, i)). The authors believe that the PL arises from the presence of a core-shell structure. In the case of MQD-150, amorphous carbon dots were obtained, and PL was ascribed to their presence (Fig. 6(g, j)). This study is the first to report the PL of $\mathrm{Ti}_{3} \mathrm{C}_{2}$ MQDs with a QY of nearly $10 \%{ }^{29}$. Xu et al..$^{34}$ prepared pristine
$\mathrm{Ti}_{3} \mathrm{C}_{2}$ MQDs and nitrogen-doped $\mathrm{Ti}_{3} \mathrm{C}_{2}$ MQDs (NMQDs) using layered $\mathrm{Ti}_{3} \mathrm{C}_{2}$ nanosheets as the parent precursors. It was proposed that the doping of heteroatoms such as nitrogen optimized the PL properties of $\mathrm{Ti}_{3} \mathrm{C}_{2}$ MQDs. In addition, they attributed the excitationdependent PL of N-MQDs to quantum confinement, which resulted in a higher QY value of up to $18.7 \%$. To understand the effect of nitrogen doping on the QY of N-MQDs, DFT calculations were employed and $\mathrm{Ti}_{3} \mathrm{C}_{2}$ MQDs terminated with "O" group were used. As shown in Fig. 7(a), the density of states of pristine MQDs showed a bandgap and a sub-gap of $0.15 \mathrm{eV}$. With $\mathrm{N}$ doping, the bandgap of N-MQDs increased because of the combination of the existing bandgap and the subgap. Fig. 7(b) shows that a chemical bond existed between $\mathrm{Ti}$ and $\mathrm{N}$ in the N-MQDs. The presence of prominent gap states increased the lifetime of the 


\section{a}
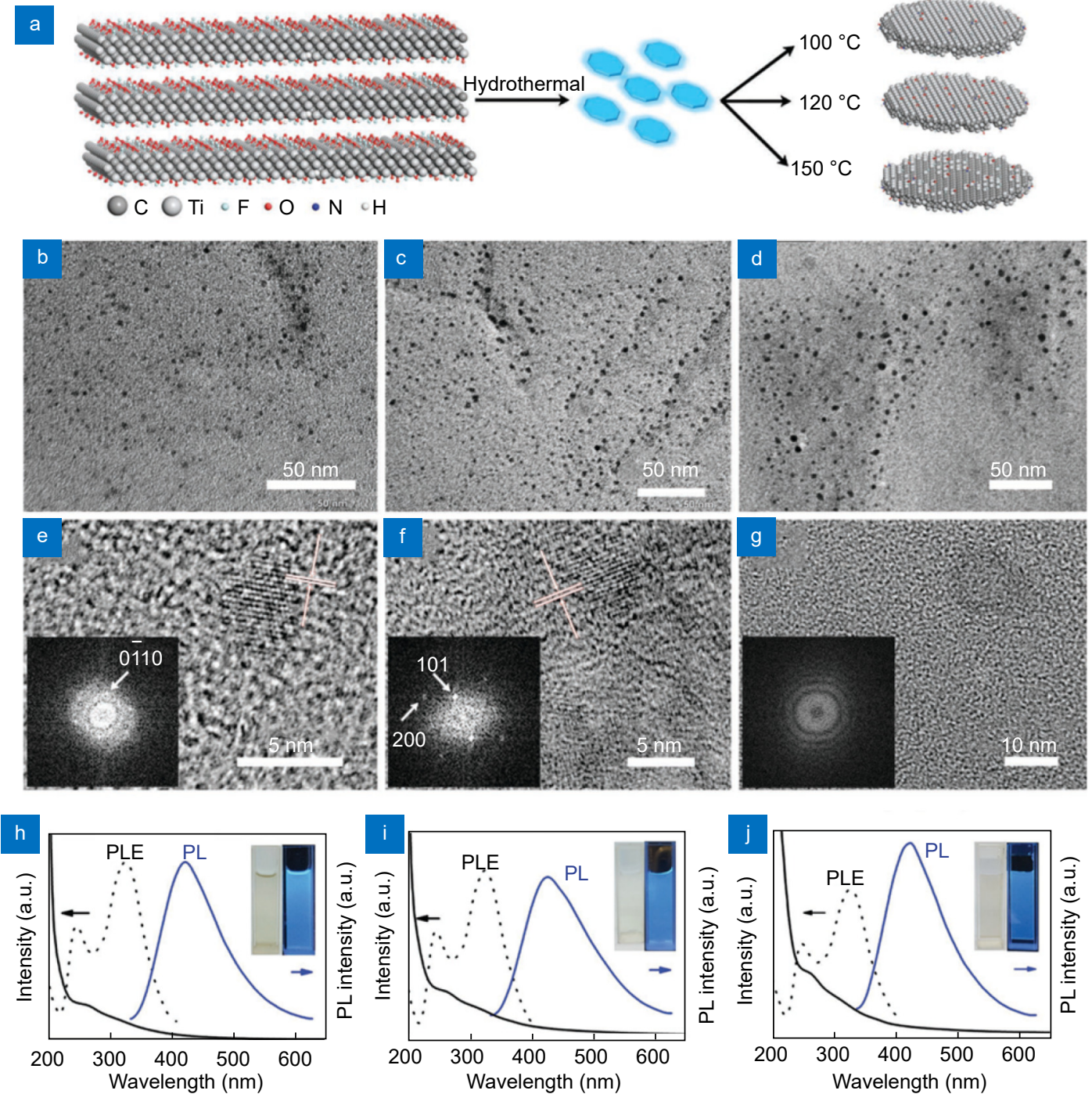

Fig. 6 | (a) MQD preparation by the hydrothermal method. TEM and HRTEM images of (b,e) MQD-100, (c,f) MQD-120, and (d,g) MQD-150. UV-vis spectra, PLE, and PL of (h) MQD-100, (i) MQD-120, and (j) MQD-150 in aqueous solutions. The figures were reproduced with permission from ref. ${ }^{29}$, Copyright 2017, John Wiley and Sons.

carriers, thus improving the QY. In conclusion, nitrogen doping caused a widening of the energy gap, which resulted in an enhanced carrier lifetime and improved QY. The work function of the N-MQDs was smaller than that of $\mathrm{Ti}_{3} \mathrm{C}_{2}$ MQDs (Fig. 7(c)), suggesting easier electron migration in N-MQDs ${ }^{34}$.

The presence of large heterogeneity during the synthesis of MQDs results in the PL properties of MQDs being affected by the size, defects, shape, functional groups, edge configuration, and heterogeneous hybridization of the carbon network ${ }^{90}$. Xu et al. ${ }^{30}$ studied the PL mechanism of sulfur- and nitrogen-doped $\mathrm{Ti}_{3} \mathrm{C}_{2}$ MQDs. They prepared sulfur- and nitrogen-doped $\mathrm{Ti}_{3} \mathrm{C}_{2}$ MQDs (SMQDs, N-MQDs, SN-MQDs) by a hydrothermal synthesis approach. The MQDs exhibited fluorescence en- hancement due to the formation of a stalwart bridge such as a hydrogen-bonded network among MQDs by bonding water on doped MQD surface. The possible molecular interaction and light emission mechanism in water were studied, as shown in Fig. 8(a). The doped $\mathrm{Ti}_{3} \mathrm{C}_{2}$ MQDs (S-MQDs, N-MQDs, SN-MQDs) were connected with each other via hydrogen bonds with water molecules, which resulted in increased lateral size of MQDs (Fig. 8(b) $)^{30}$. R. Bailey and S. Nie explained that an increase in the lateral size and the decline in the band gap due to $\pi$-electron delocalization caused a red-shift in the emission spectra ${ }^{91}$. Figure 8 (c) shows the dynamic light scattering (DLS) size distribution of the doped MQDs. Owing to the hydrogen-bonded network between the MQDs and water, the mean diameters of the SN-MQDs 

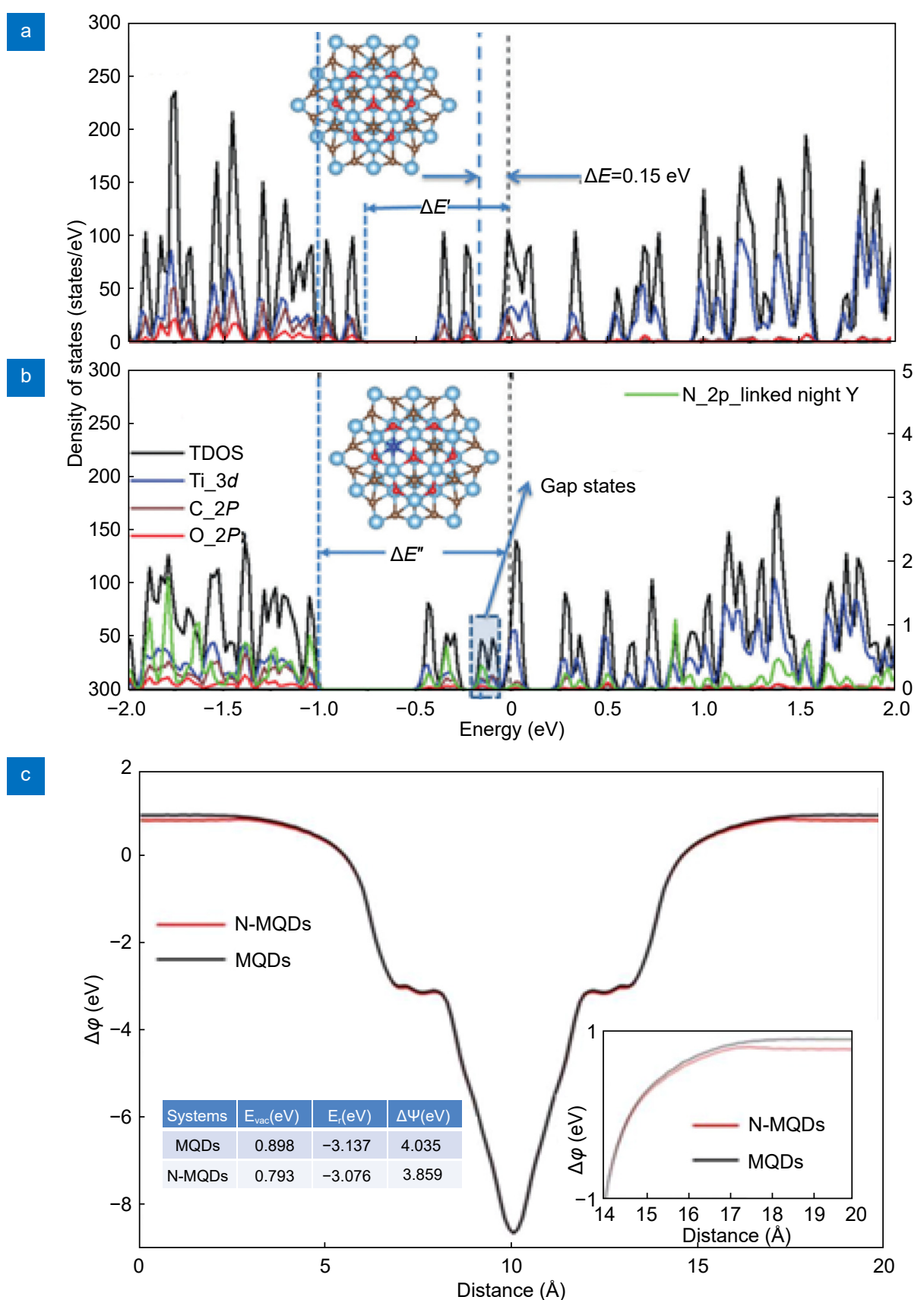

Fig. 7 | DFT calculation of total and projected density of states of (a) $\mathrm{Ti}_{3} \mathrm{C}_{2} \mathrm{O}_{2}$ QDs and (b) $\mathrm{Ti}_{3} \mathrm{C}_{2-x} \mathrm{~N}_{x} \mathrm{O}_{2}$ QDs. (c) Work function of pristine $\mathrm{Ti}_{3} \mathrm{C}_{2}$ QDs (MQDs) and N-MQDs. Figures were reproduced with permission from ref. ${ }^{34}$. Copyright 2018, Royal Society of Chemistry.

and N-MQDs hydrogen-bonded network were 129.3 and $101.7 \mathrm{~nm}$, with the QY of 7.78\% and 8.33\%, respectively. S-MQDs did not form a hydrogen-bonded network because they had particle size distribution of less than $20 \mathrm{~nm}$, except for the presence of $\mathrm{TiO}_{2}$ in the pattern. SMQDs with the smallest among the three MQDs achieved a high QY of $28.12 \%$. This suggests that with the help of surface functionalization it is possible to tune the bandgap of MQDs by controlling the lateral size during fabrication process. As the size of the MQDs became larger, the QY was reduced and the emission spectra was red-shifted. The formation of hydrogen-bonded networks led to the immobilization of the $\mathrm{C}=\mathrm{O}$ and $\mathrm{C}-\mathrm{O}$ bonds of the MQDs and strengthened the rigidity of the entire system. This resulted in an increased lateral size and enhanced fluorescence ${ }^{30}$.

Modulation of photoluminescence by surface defects, functionalization, and passivation

Surface modification and engineering are employed to 

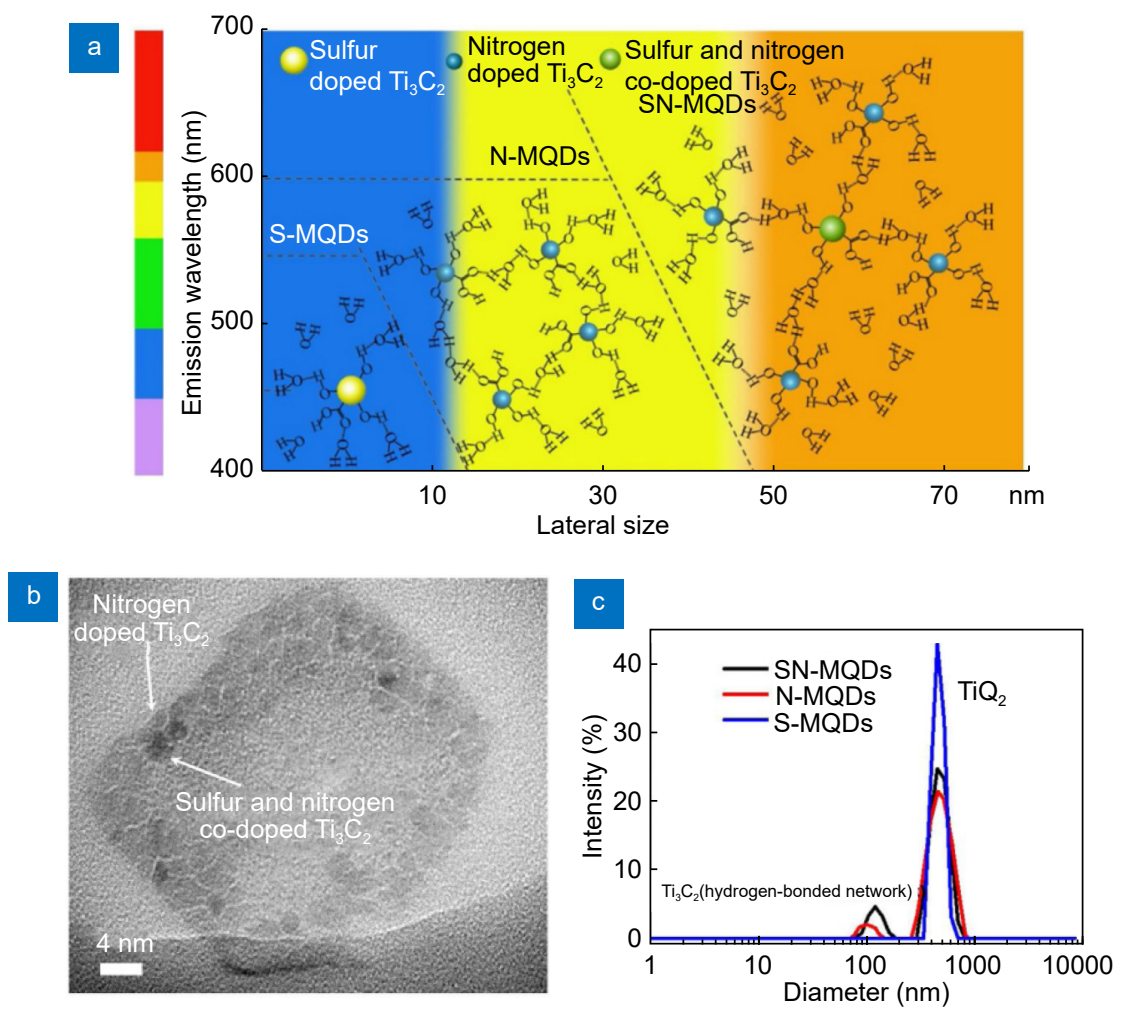

Fig. 8 | (a) Schematic of the molecular interactions and light-emitting mechanism of MQDs in water. (b) The corresponding HRTEM image of SNMQDs in relation to the mechanism. (c) DLS size distributions of the synthesized MQDs in deionized water. Figures were reproduced with permission from ref. ${ }^{30}$. Copyright 2019, Elsevier.

overcome the drawbacks of MQDs such as oxidation and aggregation. Surface engineering methods include functionalization of MQDs such as composite construction and hetero-atomic doping ${ }^{34,74,92,93}$. The surface-functionalized sites can affect the PL properties of MQDs. Chen et al. ${ }^{94}$ functionalized the surface of $\mathrm{Ti}_{3} \mathrm{C}_{2}$ QDs with polyethyleneimine by using a hydrothermal approach. The functionalized MQDs exhibited bright excitation-dependent blue PL, which was attributed to the bandgap transitions and surface defect emissions. The luminescence behavior of the $\mathrm{Ti}_{3} \mathrm{C}_{2}$ QDs was $\mathrm{pH}$-dependent, which was explained by the decrease in absorption and the increase in the non-radiation rate induced by the deprotonation of the surface defects of $\mathrm{Ti}_{3} \mathrm{C}_{2}$ QDs. The surface defect sites originated from the functionalization of MQDs with the surface passivation agent. The functionalized $\mathrm{Ti}_{3} \mathrm{C}_{2}$ QDs exhibited excitation wavelength- and pH-dependent blue PL, with a QY of 7.13\% ${ }^{94}$. Liu et al. also functionalized $\mathrm{Ti}_{3} \mathrm{C}_{2}$ MQDs with $\varepsilon$-poly-L-lysine (PLL) by sonication cutting of a $\mathrm{Ti}_{3} \mathrm{C}_{2}$ film, followed by a hydrothermal approach. They explained that the surface defects originated from the PLL favored the excitation from wavelength-dependent emissions of PLL-protected
$\mathrm{Ti}_{3} \mathrm{C}_{2}$ MQDs. The PLL-protected $\mathrm{Ti}_{3} \mathrm{C}_{2}$ MQDs exhibited a blue PL with a QY of $22 \%$ owing to the strong quantum confinement effect ${ }^{95}$.

Yang et al. synthesized $\mathrm{Nb}_{2} \mathrm{C}$ QDs by employing a pulsed ultrasound method, followed by physicochemical exfoliation in TPAOH when the $\mathrm{pH}$ reached above $6^{38}$. $\mathrm{Nb}_{2} \mathrm{C}$ QDs possess a hexagonal crystalline structure and good dispersibility. The synthesized $\mathrm{Nb}_{2} \mathrm{C}$ QDs are uniform ultra-small particles with a lateral size ranging from 1 to $5 \mathrm{~nm}$. UV-Visible spectroscopy analysis revealed a significant increase in absorption below $400 \mathrm{~nm}$. This spectral property was attributed to the size effect of $\mathrm{Nb}_{2} \mathrm{C}$ QDs, where the absorption edge of the $\mathrm{Nb}_{2} \mathrm{C}$ QDs blueshifted with a decrease in its dimensions. Strong PL excitation and emission peaks were observed at $370 \mathrm{~nm}$ and $485 \mathrm{~nm}$, respectively. $\mathrm{Nb}_{2} \mathrm{C}$ QDs emitted a bluishgreen fluorescence at $365 \mathrm{~nm}$ with a QY of $8.4 \%$. An increase in the excitation wavelength from 330 to $450 \mathrm{~nm}$ caused a red shift of the peak in the PL emission spectra of $\mathrm{Nb}_{2} \mathrm{C}$ QDs from 480 to $540 \mathrm{~nm}$. This excitation-dependent PL emission property of QDs could be attributed to surface defects and size effects, whereas the bright PL emission is ascribed to the strong quantum 
confinement resulting from the surface defects and ultrasmall lateral dimension of $\mathrm{Nb}_{2} \mathrm{C}$ QDs. The effect of $\mathrm{pH}$ on the fluorescence stability of $\mathrm{Nb}_{2} \mathrm{C}$ QDs was studied, and the fluorescence intensity did not change at $\mathrm{pH}$ $5-11$. However, a sharp decrease was observed at a $\mathrm{pH}$ below 5. The de/protonation effects of the $\mathrm{Nb}_{2} \mathrm{C}$ QDs might be a reason for this. The oxygen-containing groups are suitably deprotonated on the surface of $\mathrm{Nb}_{2} \mathrm{C}$ $\mathrm{QDs}$ at $\mathrm{pH}>5$. This deprotonation causes a high net surface negative charge, thus revoking the deterioration in fluorescence intensity. At $\mathrm{pH}<5$, however, the surface groups begin to be protonated, which leads to a reduction in the net surface charge and the formation of hydrogen bonds between the particles. As a result, the $\mathrm{Nb}_{2} \mathrm{C}$ QDs precipitate and their fluorescence intensity decreases.

Surface passivation is performed by coating the surface of QDs with another material to protect the QD core. It plays a vital role in improving the fluorescence of QDs by reducing surface defects ${ }^{96,97}$. Huang et al. ${ }^{37}$ fabricated $\mathrm{V}_{2} \mathrm{C} \mathrm{MQDs}$ via a hydrothermal method, followed by functionalization with - $\mathrm{NH}$ groups in an aqueous ammonia solution. The PL intensity of the passivated MQDs at $500 \mathrm{~nm}$ or longer wavelength was found to be enhanced five times as compared to that obtained for non-passivated MQDs. The full width at half maximum (FWHM) of the PL emission was observed to be broadened at longer wavelengths with a cutoff edge up to $700 \mathrm{~nm}$. Also, the lifetime of passivated MQDs was $6.57 \mathrm{~ns}$ but that of non-passivated MQDs was $4.99 \mathrm{~ns}$. According to the theory of finite atomic systems, $\mathrm{V}_{2} \mathrm{C}$ has few atomic layers, which makes it more susceptible to external passivation. An increase in the excitation wavelength caused luminescence peaks to red-shift, thereby decreasing the intensity. This could be attributed to the presence of different local electron states after passivation.

\section{Applications}

\section{Optoelectronic applications}

Currently, approximately $20 \%$ of the world's electricity has been reported to be consumed for lighting purposes. As the world population has increased over time, lowcost and efficient artificial lights have been in high demand $^{98}$. Inorganic semiconductor colloidal QDs have been of interest for next-generation light-emitting devices because of their high quantum efficiency and col- or purity, low-cost fabrication process, and bandgap tunability ${ }^{99}$.

However, most inorganic QDs are fabricated using heavy metals that are harmful to humans and the environment ${ }^{100}$. MQDs have been reported to be non-toxic or less toxic and thus have been used for several applications in the biomedical field ${ }^{29,68,101}$. MQDs can be used in light-emitting devices owing to their strong PL emission and non-toxicity.

MQDs have proven to be advantageous for LEDs because their convenient functionalization enables us to tune the emission wavelength and strong PL emission. $\mathrm{Xu}$ et al. ${ }^{30}$ synthesized multi-color-emitting $\mathrm{Ti}_{3} \mathrm{C}_{2} \mathrm{MQDs}$ with a single excitation at $360 \mathrm{~nm}$. The emission colors of S-, N-, and SN-doped MQD surface were blue, yellow, and orange with QYs of up to $28.12 \%, 8.33 \%$, and $7.78 \%$, respectively, making it a suitable material for multi-color LEDs. Furthermore, the differently colored MQDs can be homogenously mixed in polyvinylpyrrolidone to obtain a white LED (Fig. 9(b, c)). Huang et al. ${ }^{37}$ significantly enhanced the PL of $\mathrm{V}_{2} \mathrm{C}$ MQDs through a passivation process. The MQDs have emissions that cover almost the entire visible wavelength region. The blue, green, yellow, and red lights could be amplified and lased simultaneously under excitation below $400 \mathrm{~nm}$. This method was used to achieve a white laser using $\mathrm{V}_{2} \mathrm{C}$ MQDs. On the other hand, Lu et al. ${ }^{36}$ fabricated whiteemitting $\mathrm{Ti}_{3} \mathrm{C}_{2}$ MQDs with a QY of 9.36\%, and twophoton fluorescence was also reported for these MQDs (Fig. 9(a)). The spectral full width at half maximum exceeded $220 \mathrm{~nm}$, covering a large range of the visible wavelength region. The white LEDs fabricated using the MQDs with this method emitted stable white light close to the center of the chromaticity diagram (Fig. 9(d, e)).

\section{Photoluminescence-based sensors}

The detection of metal ions and biological components by monitoring the biological system at the cellular level is beneficial for a healthy life. Furthermore, the release of pollutants from industrial waste has caused serious environmental problems. Therefore, designing a sensitive and selective sensor for specific targets is important for maintaining the biological and environmental systems ${ }^{102}$. Among the methods developed for bio detection, PLbased sensors are preferred owing to their high sensitivity, good reproducibility, and short analysis time, along with a small sample size ${ }^{103-106}$. The fabrication of MQDs has further promoted the application of MXene-derived 

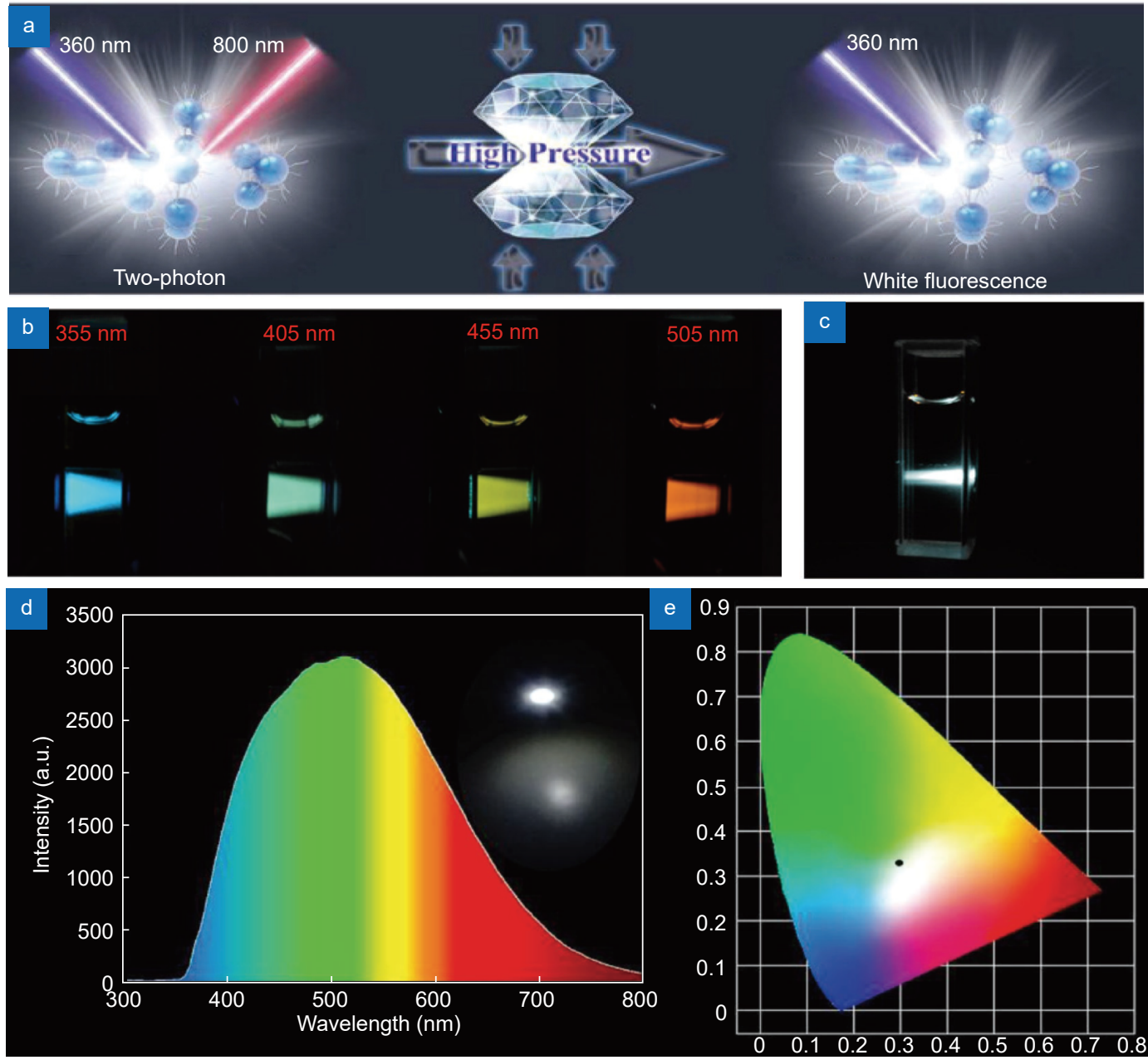

Fig. 9 | (a) White emission of $\mathrm{Ti}_{3} \mathrm{C}_{2}$. (b) PL color of the $\mathrm{V}_{2} \mathrm{C}$ QDs under different excitation wavelengths. (c) $\mathrm{V}_{2} \mathrm{C}$ MQDs colloid under $355 \mathrm{~nm}$ pulsed laser pumping. (d) Emission spectrum of white LED (e) Chromaticity diagram (CIE 1931) coordinates of the white LED (0.30, 0.34). Figures were reproduced with from: (a), (d), (e) ref. ${ }^{36}$. Copyright 2019, WILEY-VCH; (b), (c) ref. ${ }^{37}$. Copyright 2019, John Wiley and Sons.

materials as they exhibit strong PL both in solid state and aqueous solution with small sizes $(<10 \mathrm{~nm})^{30}$. Furthermore, MQDs are known to be non-toxic due to the absence of heavy metal ions which made them less harmful to the environment than most inorganic QDs ${ }^{100,107,108}$, and thus promising materials for PL-based sensors.

MQDs were tested for their high sensitivity and selectivity by using different metal ions $\left(\mathrm{Fe}^{3+}, \mathrm{Fe}^{2+}, \mathrm{Ca}^{2+}\right.$, $\mathrm{Cd}^{2+}, \mathrm{Mg}^{2+}, \mathrm{Na}^{2+}, \mathrm{Sn}^{2+}, \mathrm{Co}^{2+}, \mathrm{Ni}^{2+}, \mathrm{Cu}^{2+}, \mathrm{Zn}^{2+}, \mathrm{Pb}^{2+}, \mathrm{Al}^{3+}$, $\left.\mathrm{Cr}^{3+}\right)^{109,34}$. The MQDs showed efficient detection for $\mathrm{Fe}^{3+109,34}, \mathrm{Zn}^{2+29}, \mathrm{Cu}^{2+110}, \mathrm{Ag}^{+110}$, and $\mathrm{Mn}^{2+110}$. The readily functionalized MQDs have oxygenous groups, for example, hydroxyl, carboxyl, and carbonyl groups, at the surface and edge. These functional groups have a highaffinity interaction with metal ions, which induces aggregation on well-dispersed MQDs (Fig. 10(b)). The metal ions act as bridges connecting individual MQDs together. This interaction results in the PL quenching of the MQDs ${ }^{111}$. MQDs were also used for biological detection. $\mathrm{Ti}_{3} \mathrm{C}_{2}$ MQDs were used to detect an alkaline phosphatase (ALP) assay ${ }^{112}$. The emission spectrum of $\mathrm{Ti}_{3} \mathrm{C}_{2}$ overlapped with the absorption spectrum of ALP, which comes from p-nitrophenol (Fig. 10(d)), a chemical produced from the ALP-catalyzed dephosphorylation of the substrate. PL quenching of $\mathrm{Ti}_{3} \mathrm{C}_{2}$ QDs was due to the inner filter effect. PL intensity of $\mathrm{Ti}_{3} \mathrm{C}_{2}$ MQDs decreased with an increase in the ALP concentration (from 0 to 50 $\mathrm{U} \mathrm{L}^{-1}$ ), and a good linearity between the quenching efficiency and ALP concentration was obtained in the range of 0.1-2.0 U L-1. A pH-dependent PL behavior was also observed based on ethylenimine-functionalized $\mathrm{Ti}_{3} \mathrm{C}_{2}$ QDs (Fig. 10(c)), which could be used for pH sensing and quantitative detection of the intracellular $\mathrm{pH}$ values $^{94}$.

It was observed that cysteine, serine, arginine, ascorbic acid, dopamine, $\mathrm{H}_{2} \mathrm{O}_{2}$, and various other metal ions 
have little or no effect on PL quenching of MQDs (Fig. 10(a)). The presence of both $\mathrm{H}_{2} \mathrm{O}_{2}$ and $\mathrm{Fe}^{2+}$ was found to reduce the PL intensity of nitrogen-doped $\mathrm{Ti}_{3} \mathrm{C}_{2}$ MQDs. However, there was no observable behavior in the presence of either $\mathrm{H}_{2} \mathrm{O}_{2}$ or $\mathrm{Fe}^{2+}{ }^{34}$. Glutathione-functionalized $\mathrm{Ti}_{3} \mathrm{C}_{2}\left(\mathrm{GSH}-\mathrm{Ti}_{3} \mathrm{C}_{2}\right)$ MQDs were used to detect uric acid based on the oxidation of uric acid by uricase to allantoin and $\mathrm{H}_{2} \mathrm{O}_{2}$. The overlap of the $\mathrm{PL}$ emission of GSH- $\mathrm{Ti}_{3} \mathrm{C}_{2}$ MQDs centered at $430 \mathrm{~nm}$ and large absorption of 2,3-diaminophenazine (oxOPD) around $425 \mathrm{~nm}$ induced a fluorescence resonance energy transfer between the GSH-Ti ${ }_{3} \mathrm{C}_{2}$ MQDs. The emission of GSH$\mathrm{Ti}_{3} \mathrm{C}_{2}$ MQDs gradually decreased while the emission of oxOPD at $568 \mathrm{~nm}$ increased with an increase in uric acid concentration $^{113}$.

\section{Bioimaging}

Bioimaging is a powerful technique that can effectively provide clear biological information ${ }^{114}$. Since the application of QDs in biological fields, extensive research has led to the discovery of more versatile applications such as bioimaging and biodetection ${ }^{115,116}$. However, issues related to toxicity and non-biodegradability remain a challenge in designing a biocompatible QD-based bioima- ging tool ${ }^{117,108}$. MQDs are promising candidates for improving the quality of bioimaging because of their strong PL, small size ( $<10 \mathrm{~nm})$, non-toxicity, and biodegradability $29,31,32,68,101$. Furthermore, MQDs inherit biocompatibility and anti-bacterial efficiency from MXenes, which makes them a potential candidate for bioimaging when compare with most inorganic QDs ${ }^{100,107,108,117,118}$. The first reported $\mathrm{Ti}_{3} \mathrm{C}_{2}$ MQDs were used for multicolor cellular imaging $^{29}$. The MQDs exhibited excitation-dependent PL spectra in an aqueous solution with PLQYs of approximately $10 \%$. After ingestion by RAW264.7 cells via endocytosis, emission of blue, green, and red colors was observed in the confocal images at excitation wavelengths of 405, 488, and $543 \mathrm{~nm}$, respectively (Fig. 11(a)). Furthermore, the PL of MQDs was weaker in the nucleus region when compared with that in the cell membrane and cytoplasm, which indicates that the MQDs could readily enter the cell without penetrating through the nucleus to avoid genetic damage. The survival rates of RAW264.7 cells when incubated with MQDs for $48 \mathrm{~h}$ exceeded 90\%, confirming the low cytotoxicity.

Cao et al. ${ }^{68}$ prepared $\mathrm{V}_{2} \mathrm{C}$ MQDs and successfully functionalized them with polyethylene glycol and TAT peptide to perform bioimaging of MCF-7 and NHDF
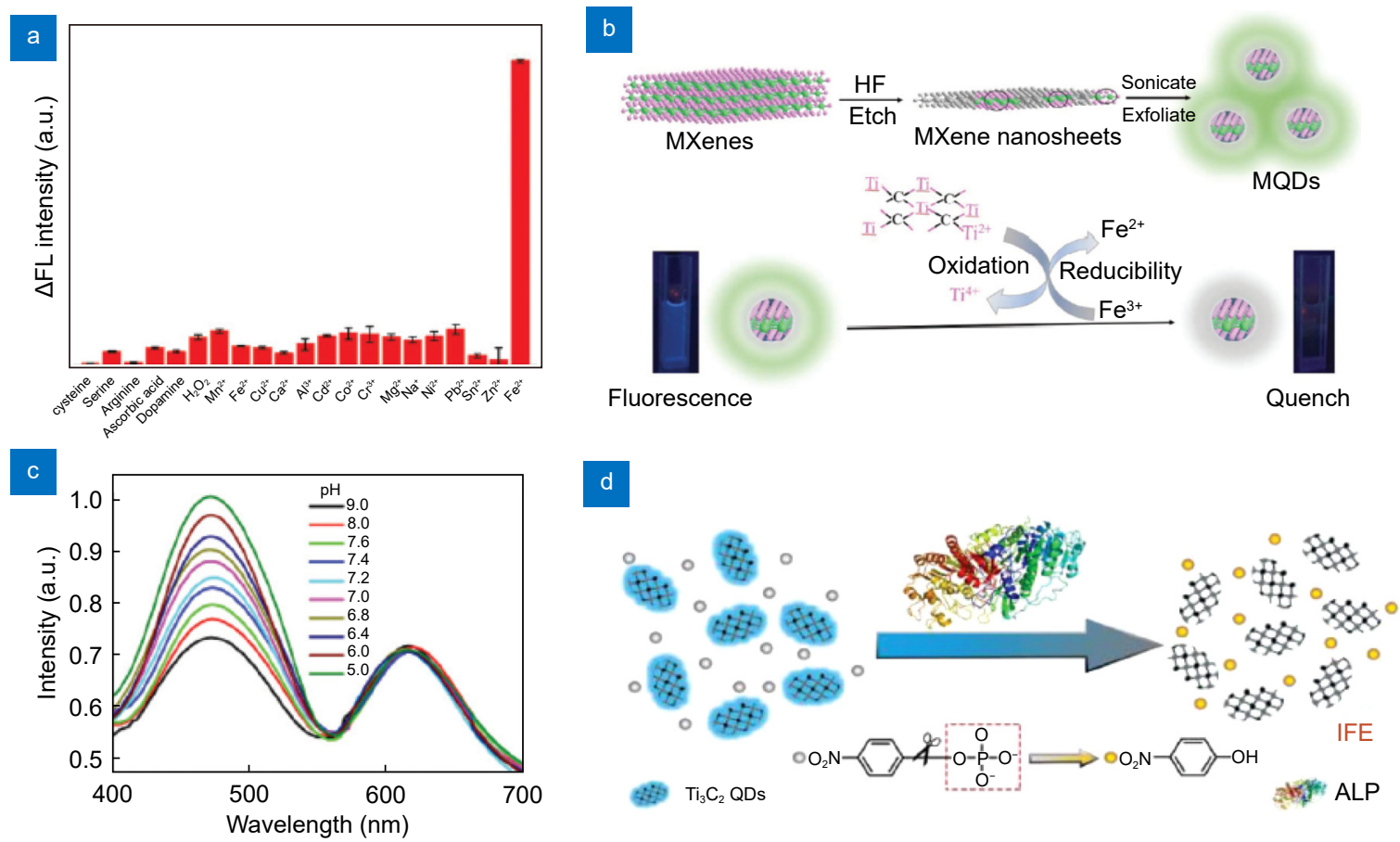

Fig. 10 | (a) The normalized fluorescence intensity of MQDs at $380 \mathrm{~nm}$ in the presence of various analytes. (b) The MQD synthesis process and working principle for $\mathrm{Fe}^{3+}$ sensing. (c) Normalized $\mathrm{PL}$ spectra of $\left[\mathrm{Ru}(\mathrm{dpp})_{3}\right] \mathrm{Cl}_{2}$ and $\mathrm{Ti}_{3} \mathrm{C}_{2} \mathrm{QDs}$ in a buffer solution with different pH values $\left(\lambda_{\mathrm{ex}}=\right.$ $350 \mathrm{~nm}$ ). (d) The principle of $\mathrm{Ti}_{3} \mathrm{C}_{2}$ QD-based fluorescence assay for ALP activity. The figures were reproduced with permission from: (a), (b) ref. ${ }^{109}$, (c) ref. ${ }^{94}$ and (d) ref. ${ }^{112}$, Royal Society of Chemistry. 
cells. To test the cell uptake and nucleus target of the MQDs, the cell membrane was dyed with $\mathrm{DiO}$ (green) and the exosome membranes were stained with DiI (red). The overlay of blue PL of $\mathrm{V}_{2} \mathrm{C}$ with membranes dyed with $\mathrm{DiO}$ and DiI (Fig. 11(d)) showed that the MQDs entered both MCF-7 and NHDF cells via the endocytic uptake pathway. This pathway is preferable for bioimaging because of the weak nucleus-targeting ability due to inefficient lysosome escape.

Cellular imaging of N- and P-functionalized $\mathrm{Ti}_{3} \mathrm{C}_{2}$ MXene quantum dots (N,P-MQDs) was carried out by Quan et al. ${ }^{110}$ The THP-1 macrophages were incubated with $25 \mu \mathrm{g} \cdot \mathrm{mL}^{-1}$ of N,P-MQDs for $24 \mathrm{~h}$. The N,P-MQDs demonstrated high efficiency for the detection of $\mathrm{Cu}^{2+}$ due to the inner filter effect. When the $\mathrm{Cu}^{2+}$ ions were captured by the amino group of the N,P-MQDs, an absorbent complex was formed on the surface of the N,PMQDs. This resulted in significant quenching of the strong emission from the N,P-MQDs at $560 \mathrm{~nm}$ (Fig. $11(b, c))$. A decrease in the PL intensity was observed upon addition of up to $100 \mu \mathrm{M} \mathrm{Cu}^{2+}$ of N,P-MQDs.

\section{Conclusion and perspective}

The synthesis of MQDs has raised considerable interest because they not only retain the properties of MXene but also demonstrate light-emitting properties. Currently, studies on light-emitting MQDs have shown progress in terms of synthesis methods to fabricate multicolor-PL-
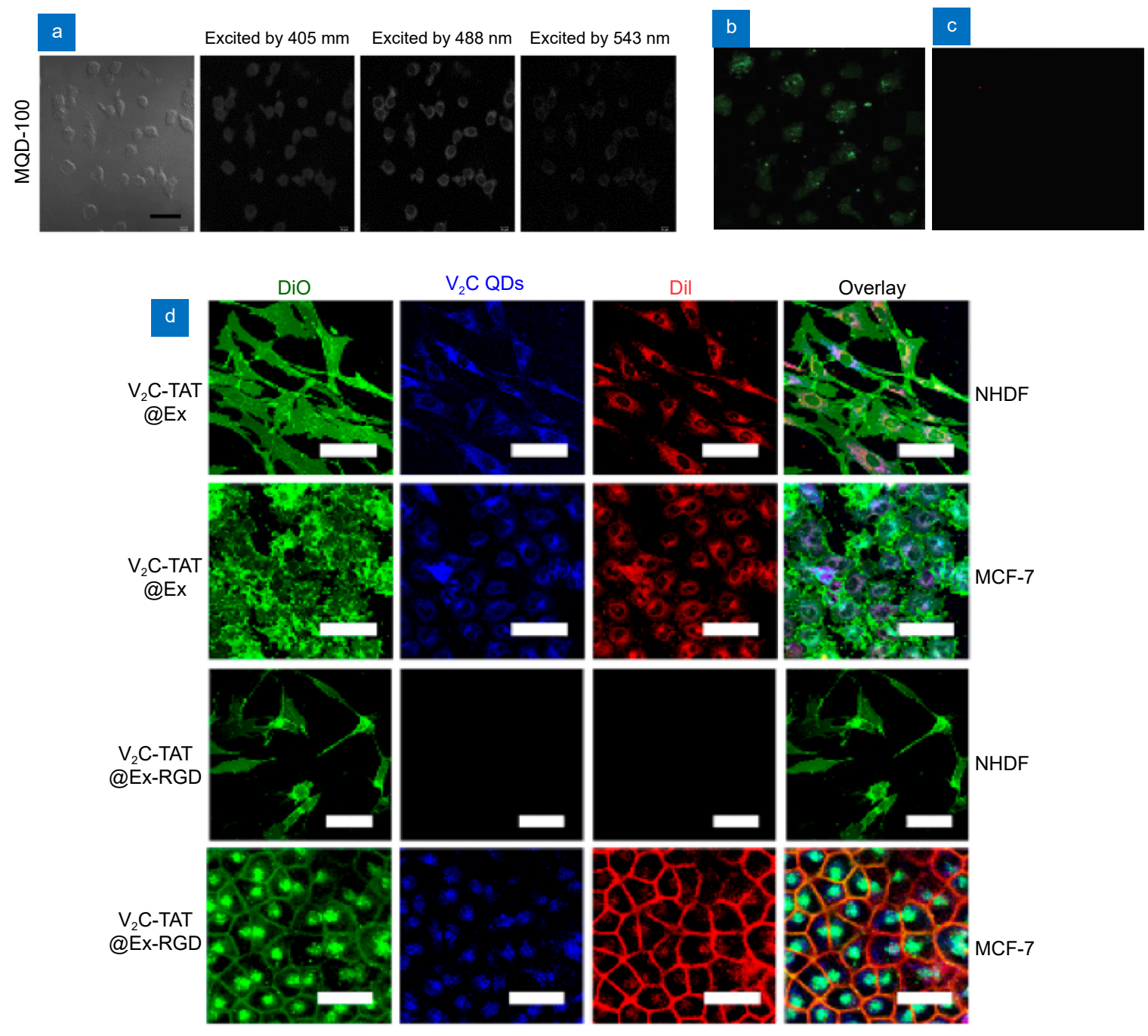

Fig. 11 | (a) Bright-field imaging of RAW264.7 cells and confocal imaging of RAW264.7 cells incubated with MQD-100 at $405 \mathrm{~nm}, 488 \mathrm{~nm}$, and $543 \mathrm{~nm}$ excitation. (b),(c) Fluorescent imaging $(E x=488 \mathrm{~nm}$ ) of the THP-1 monocytes incubated (b) with N,P-MQDs (c) without N,P-MQDs (d) CLSM images of MCF-7 and NHDF cells after incubation of $\mathrm{V}_{2} \mathrm{C}$-TAT@Ex or $\mathrm{V}_{2} \mathrm{C}$-TAT@Ex-RGD (Scale bar: $40 \mu \mathrm{m}$ ). The figures were reproduced with permission from: (a) ref. ${ }^{29}$. Copyright 2017, John Wiley and Sons; (b),(c) ref. ${ }^{110}$. Copyright 2019, Royal Society of Chemistry; (d) ref. ${ }^{68}$. Copyright 2019, American Chemical Society. 
emitting MQDs, and the highest reported QY has been 28.12\%. Despite its excellent properties, MXene does not possess PL emission, which limits its applications. However, MQDs overcome this limitation and have thus found applications in optoelectronic devices, PL-based sensors, and bioimaging. Regardless of the great progress, research on MQDs is still in its early stages, and the PL mechanism has not yet been fully comprehended. Comprehensive studies are required for better understanding considering the challenges for their potential applications.

\section{Synthesis of nitride and carbon nitride MQDs}

Currently, over 100 types of MAX phases have been reported. Among these, more than 30 kinds of MXenes have been experimentally obtained since $2011^{7}$, and many more are expected to be reported according to theoretical predictions $^{119}$. Even so, the types of MQDs that have been fabricated have been mostly derived from the carbide group of MXene. Only one nitride MQD has been reported to have a broad range of absorption from UV to IR wavelengths, but no PL observations have been reported $^{64}$. In addition, there are no reports on carbon nitride MQDs.

With the current advances in research on 2D-derived QDs (2D-QDs), various methods can be applied to synthesize different types of MQDs from different groups of MXenes, including carbon, nitride, and carbon nitride. It is expected that with the large number of currently available MXenes, more interesting properties or improved properties could be observed, which would help to advance the research on MQDs.

\section{Synthesis methods of light-emitting MQDs}

There are two main approaches for synthesizing MQDs: top-down and bottom-up. Among these, only the topdown method has successfully yielded light-emitting $\mathrm{MQDs}^{32}$. We emphasize the need to explore more methods to further advance the research on MQDs. The reason is that the PL behavior of MQDs is highly dependent on the functionalization, parent precursors, and synthesis method.

By controlling these three variables and understanding the surface chemistry, it is possible to design MQDs with desirable properties. Currently, only $\mathrm{Ti}_{3} \mathrm{C}_{2}, \mathrm{Nb}_{2} \mathrm{C}$, and $\mathrm{V}_{2} \mathrm{C}$ MQDs have been reported to show light-emitting properties. By varying the synthesis procedure, light-emitting MQDs with more interesting properties could be fabricated.

\section{Optoelectronic applications}

We focused on light-emitting MQDs in this review because MQDs have promising future prospects in optoelectronic applications. The increase in energy consumed every year is worrisome because the world still relies on fossil fuels as the main energy source, which is scarce and sometimes hazardous. Thus, finding a cheap and clean energy source that can provide high power conversion efficiency is in high demand. MQDs not only have shown potential as a material to be used in efficient light-emitting devices but also exhibit low toxicity, making them potential material for bio-applications. However, the QY of MQDs is low and needs improvement. Furthermore, the emission and absorption of MQDs are tuned mostly by functionalization, while the tunability of semiconductors can be simply achieved by changing the reaction temperature and/or time. Understanding the origin of the PL of MQDs is the main key to fully explore the potential of MQDs for optoelectronic applications.

MXene is known to be a suitable material for solar cells. Currently, researchers have used MXene as one of the electron transport layers in perovskite solar cells (PSCs) in order to increase the short-circuit current density $\left(\mathrm{J}_{\mathrm{sc}}\right)$, open-circuit voltage $\left(\mathrm{V}_{\mathrm{oc}}\right)$, and fill factor (FF), resulting in a much higher power conversion efficiency (PCE) compared with that of PSCs without MXene layers ${ }^{119,120}$. The merits of fabricating 2D-QDs are that they retain the existing properties of its parent precursors, making it usable for the same applications as those of the $2 \mathrm{D}$ materials. As per our knowledge, there is no published work on using MQDs as active materials for solar cells.

Currently, there exist challenging issues related to device compatibility because most semiconductor QDs show a significantly low quantum efficiency when used for devices ${ }^{99}$. Research on MQDs is new compared with that on other QDs, especially for device applications.

\section{Medical applications}

For medical applications, the strongest advantage of MQDs over conventional inorganic semiconductor QDs is their low toxicity. MQDs have been used in the medical field, for example, in photothermal therapy for cancer ${ }^{68}$, immunomodulation, regenerative medicine, biosensors, biolabeling $^{110}$ and bioimaging ${ }^{29}$. However, most of the 
tests conducted were only for a short term. More vigorous clinical trials should be conducted to confirm that the MQDs do not incur any potential harmful health risks. Although MQDs are biodegradable and can be removed from biological systems through excretion, there is a limitation for applications that require long sustainability.

\section{References}

1. Novoselov KS, Geim AK, Morozov SV, Jiang D, Zhang Y et al. Electric field effect in atomically thin carbon films. Science $\mathbf{3 0 6}$, 666-669 (2004).

2. Geim AK, Novoselov KS. The rise of graphene. Nat Mater $\mathbf{6}$, 183-191 (2007).

3. Benka SG. Two-dimensional atomic crystals. Phys Today $\mathbf{5 8}$, 9 (2005).

4. Mak KF, Lee C, Hone J, Shan J, Heinz TF. Atomically thin $\mathrm{MoS}_{2}$ : a new direct-gap semiconductor. Phys Rev Lett 105, 136805 (2010).

5. Ma RZ, Sasaki T. Nanosheets of oxides and hydroxides: ultimate 2D charge-bearing functional crystallites. Adv Mater 22, 5082-5104 (2010).

6. Lv QS, Yan FG, Wei X, Wang KY. High-performance, self-driven photodetector based on graphene sandwiched GaSe/WS 2 heterojunction. Adv Opt Mater 6, 1700490 (2018).

7. Lv QS, Yan FG, Mori N, Zhu WK, He C et al. Interlayer bandto-band tunneling and negative differential resistance in van der Waals BP/InSe field-effect transistors. Adv Funct Mater $\mathbf{3 0}$, 1910713 (2020).

8. Hu C, Zhang D, Yan FG, Li YC, Lv QS et al. From two- to multi-state vertical spin valves without spacer layer based on $\mathrm{Fe}_{3} \mathrm{GeTe}_{2}$ van der Waals homo-junctions. Sci Bull 65, 1072-1077 (2020).

9. Naguib M, Kurtoglu M, Presser V, Lu J, Niu JJ et al. Two-dimensional nanocrystals produced by exfoliation of $\mathrm{Ti}_{3} \mathrm{AlC}_{2}$. Adv Mater 23, 4248-4253 (2011).

10. Hantanasirisakul K, Gogotsi $Y$. Electronic and optical properties of $2 \mathrm{D}$ transition metal carbides and nitrides (MXenes). $A d v$ Mater 30, 1804779 (2018).

11. Naguib M, Mochalin VN, Barsoum MW, Gogotsi Y. 25th anniversary article: MXenes: a new family of two-dimensional materials. Adv Mater 26, 992-1005 (2014).

12. Urbankowski $\mathrm{P}$, Anasori $\mathrm{B}$, Makaryan $\mathrm{T}$, Er DQ, Kota $\mathrm{S}$ et al. Synthesis of two-dimensional titanium nitride $\mathrm{Ti}_{4} \mathrm{~N}_{3}$ (MXene). Nanoscale 8, 11385-11391 (2016).

13. Zhang $\mathrm{T}$, Pan LM, Tang H, Du F, Guo YH et al. Synthesis of two-dimensional $\mathrm{Ti}_{3} \mathrm{C}_{2} \mathrm{~T}_{x}$ MXene using $\mathrm{HCl}+\mathrm{LiF}$ etchant: enhanced exfoliation and delamination. J Alloys Compd 695, 818-826 (2017).

14. Soundiraraju B, George BK. Two-dimensional titanium nitride $\left(\mathrm{Ti}_{2} \mathrm{~N}\right)$ MXene: SYNTHESIS, characterization, and potential application as surface-enhanced raman scattering substrate. ACS Nano 11, 8892-8900 (2017).

15. Naguib M, Unocic RR, Armstrong BL, Nanda J. Large-scale delamination of multi-layers transition metal carbides and carbonitrides "MXenes". Dalton Trans 44, 9353-9358 (2015).

16. Shahzad F, Alhabeb M, Hatter CB, Anasori B, Hong SM et al.
Electromagnetic interference shielding with 2D transition metal carbides (MXenes). Science 353, 1137-1140 (2016).

17. Dong YF, Wu ZS, Zheng SH, Wang XH, Qin JQ et al. $\mathrm{Ti}_{3} \mathrm{C}_{2}$ MXene-derived sodium/potassium titanate nanoribbons for high-performance sodium/potassium ion batteries with enhanced capacities. ACS Nano 11, 4792-4800 (2017).

18. Yang QJ, GAO W, Zhong W, Tao ML, Qi YR et al. A synergistic $\mathrm{Bi}_{2} \mathrm{~S}_{3} / \mathrm{MXene}$ composite with enhanced performance as an anode material of sodium-ion batteries. New J Chem 44, 3072-3077 (2020).

19. Li RY, Zhang LB, Shi L, Wang P. MXene $\mathrm{Ti}_{3} \mathrm{C}_{2}$ : an effective 2D light-to-heat conversion material. ACS Nano 11, 3752-3759 (2017).

20. Chaudhuri K, Alhabeb M, Wang ZX, Shalaev VM, Gogotsi Y et al. Highly broadband absorber using plasmonic titanium carbide (MXene). ACS Photonics 5, 1115-1122 (2018).

21. Ying GB, Dillon AD, Fafarman AT, Barsoum MW. Transparent, conductive solution processed spincast $2 \mathrm{D} \mathrm{Ti}_{2} \mathrm{CT}_{x}$ (MXene) films. Mater Res Lett 5, 391-398 (2017).

22. An H, Habib T, Shah S, Gao HL, Radovic M et al. Surface-agnostic highly stretchable and bendable conductive MXene multilayers. Sci Adv 4, eaaq0118 (2018).

23. Jiang XT, Kuklin AV, Baev A, Ge YQ, Ågren $\mathrm{H}$ et al. Two-dimensional MXenes: from morphological to optical, electric, and magnetic properties and applications. Phys Rep 848, $1-58$ (2020).

24. Xu YH, Wang XX, Zhang WL, Lv F, Guo SJ. Recent progress in two-dimensional inorganic quantum dots. Chem Soc Rev 47, 586-625 (2018)

25. Zhang ZP, Zhang J, Chen N, Qu LT. Graphenequantum dots: an emerging material for energy-related applications and beyond. Energy Environ Sci 5, 8869-8890 (2012).

26. Xu SJ, Li D, Wu PY. One-pot, facile, and versatile synthesis of monolayer $\mathrm{MoS}_{2} / \mathrm{WS}_{2}$ quantum dots as bioimaging probes and efficient electrocatalysts for hydrogen evolution reaction. Adv Funct Mater 25, 1127-1136 (2015).

27. Huang JM, Kelley DF. Synthesis and characterization of $\mathrm{MoSe}_{2}$ and $\mathrm{WSe}_{2}$ nanoclusters. Chem Mater 12, 2825-2828 (2000).

28. Huo BB, Liu BP, Chen T, Cui L, Xu GF et al. One-step synthesis of fluorescent boron nitride quantum dots via a hydrothermal strategy using melamine as nitrogen source for the detection of ferric ions. Langmuir 33, 10673-10678 (2017).

29. Xue Q, Zhang HJ, Zhu MS, Pei ZX, Li HF et al. Photoluminescent $\mathrm{Ti}_{3} \mathrm{C}_{2}$ MXene quantum dots for multicolor cellular imaging. Adv Mater 29, 1604847 (2017).

30. Xu Q, Yang WJ, Wen YY, Liu SK, Liu Z et al. Hydrochromic full-color MXene quantum dots through hydrogen bonding toward ultrahigh-efficiency white light-emitting diodes. Appl Mater Today 16, 90-101 (2019).

31. Shao JD, Zhang J, Jiang C, Lin J, Huang P. Biodegradable titanium nitride MXene quantum dots for cancer phototheranostics in NIR-I/II biowindows. Chem Eng J 400, 126009 (2020).

32. Shao BB, Liu ZF, Zeng GM, Wang H, Liang QH et al. Two-dimensional transition metal carbide and nitride (MXene) derived quantum dots (QDs): synthesis, properties, applications and prospects. J Mater Chem A 8, 7508-7535 (2020).

33. Wang ZQ, Xuan JN, Zhao ZG, Li QW, Geng FX. Versatile cutting method for producing fluorescent ultrasmall MXene 
sheets. ACS Nano 11, 11559-11565 (2017).

34. Xu Q, Ding L, Wen YY, Yang WJ, Zhou HK et al. High photoluminescence quantum yield of $18.7 \%$ by using nitrogen-doped $\mathrm{Ti}_{3} \mathrm{C}_{2}$ MXene quantum dots. J Mater Chem C 6, 6360-6369 (2018).

35. Guan QW, Ma JF, Yang WJ, Zhang R, Zhang XJ et al. Highly fluorescent $\mathrm{Ti}_{3} \mathrm{C}_{2}$ MXene quantum dots for macrophage labeling and $\mathrm{Cu}^{2+}$ ion sensing. Nanoscale 11, 14123-14133 (2019).

36. Lu SY, Sui LZ, Liu Y, Yong X, Xiao GJ et al. White photoluminescent $\mathrm{Ti}_{3} \mathrm{C}_{2}$ MXene quantum dots with two-photon fluorescence. Adv Sci 6, 1801470 (2019).

37. Huang DP, Xie Y, Lu DZ, Wang ZY, Wang JY et al. Demonstration of a white laser with $\mathrm{V}_{2} \mathrm{C}$ MXene-based quantum dots. Adv Mater 31, 1901117 (2019).

38. Yang GH, Zhao JL, Yi SZ, Wan XJ, Tang JN. Biodegradable and photostable $\mathrm{Nb}_{2} \mathrm{C}$ MXene quantum dots as promising nanofluorophores for metal ions sensing and fluorescence imaging. Sens Actuators B Chem 309, 127735 (2020).

39. Liu ZM, Wu ED, Wang JM, Qian YH, Xiang HM et al. Crystal structure and formation mechanism of $\left(\mathrm{Cr}_{2 / 3} \mathrm{Ti}_{1 / 3}\right)_{3} \mathrm{AlC}_{2} \mathrm{MAX}$ phase. Acta Mater 73, 186-193 (2014).

40. Zhang CF, Ma YL, Zhang XT, Abdolhosseinzadeh S, Sheng $\mathrm{HW}$ et al. Two - dimensional transition metal carbides and nitrides (MXenes): synthesis, properties, and electrochemical energy storage applications. Energy Environ Mater 3, 29-55 (2020).

41. Pietzka MA, Schuster JC. Summary of constitutional data on the aluminum-carbon-titanium system. J Phase Equilibria 15, 392-400 (1994)

42. Atkinson HV, Davies S. Fundamental aspects of hot isostatic pressing: an overview. Metall Mater Trans A 31, 2981-3000 (2000).

43. Tzenov NV, Barsoum MW. Synthesis and characterization of $\mathrm{Ti}_{3} \mathrm{AlC}_{2}$. J Am Ceram Soc 83, 825-832 (2000).

44. Wang $\mathrm{XH}$, Zhou YC. Oxidation behavior of $\mathrm{Ti}_{3} \mathrm{AlC}_{2}$ at 1000-1400 ${ }^{\circ} \mathrm{C}$ in air. Corros Sci 45, 891-907 (2003).

45. Shuck CE, Han MK, Maleski K, Hantanasirisakul K, Kim SJ et al. Effect of $\mathrm{Ti}_{3} \mathrm{AIC}_{2} \mathrm{MAX}$ phase on structure and properties of resultant $\mathrm{Ti}_{3} \mathrm{C}_{2} \mathrm{~T}_{X}$ MXene. ACS App/ Nano Mater 2, 3368-3376 (2019).

46. Naguib M, Halim J, Lu J, Cook KM, Hultman L et al. New twodimensional niobium and vanadium carbides as promising materials for Li-lon batteries. J Am Chem Soc 135, 15966-15969 (2013).

47. Schuster JC, Nowotny $\mathrm{H}$. Investigations of the ternary systems ( $\mathrm{Zr}, \mathrm{Hf}, \mathrm{Nb}, \mathrm{Ta})-\mathrm{Al}-\mathrm{C}$ and studies on complex carbides. $\mathrm{Z}$ Metallkd 71, 341-346 (1980).

48. Kovalev ID, Miloserdov PA, Gorshkov VA, Kovalev DY. Synthesis of $\mathrm{Nb}_{2} \mathrm{AIC}$ MAX phase by SHS metallurgy. Russ $J$ NonFerrous Met 61, 126-131 (2020).

49. Salama I, El-Raghy T, Barsoum MW. Synthesis and mechanical properties of $\mathrm{Nb}_{2} \mathrm{AIC}$ and $(\mathrm{Ti}, \mathrm{Nb})_{2} \mathrm{AIC}$. J Alloys Compd $\mathbf{3 4 7}$, 271-278 (2002)

50. Zhang W, Travitzky N, Hu C, Zhou Y, Greil P. Reactive hot pressing and properties of Nb2AIC. J. Am. Ceram. Soc 92, 2396-2399 (2009).

51. Zhou WB, Li K, Zhu JQ, Tian SQ. Rapid synthesis of highly pure $\mathrm{Nb}_{2} \mathrm{AIC}$ using the spark plasma sintering technique. $J$ Phys Chem Solids 120, 218-222 (2018).
52. Alhabeb M, Maleski K, Anasori B, Lelyukh P, Clark L et al. Guidelines for synthesis and processing of two-dimensional titanium carbide $\left(\mathrm{Ti}_{3} \mathrm{C}_{2} \mathrm{~T}_{x} \mathrm{MXene}\right)$. Chem Mater 29, 7633-7644 (2017).

53. Wang L, Tao WQ, Yuan LY, Liu ZR, Huang Q et al. Rational control of the interlayer space inside two-dimensional titanium carbides for highly efficient uranium removal and imprisonment. Chem Commun 53, 12084-12087 (2017).

54. Pang JB, Mendes RG, Bachmatiuk A, Zhao L, Ta HQ et al. Applications of $2 \mathrm{D}$ MXenes in energy conversion and storage systems. Chem Soc Rev 48, 72-133 (2019).

55. Lipatov A, Alhabeb M, Lukatskaya MR, Boson A, Gogotsi Y et al. Effect of synthesis on quality, electronic properties and environmental stability of individual monolayer $\mathrm{Ti}_{3} \mathrm{C}_{2}$ MXene flakes. Adv Electron Mater 2, 1600255 (2016).

56. Zhang CF, Cui YY, Song L, Liu XF, Hu ZB. Microwave assisted one-pot synthesis of graphene quantum dots as highly sensitive fluorescent probes for detection of iron ions and $\mathrm{pH}$ value. Talanta 150, 54-60 (2016).

57. Li Z, Qin P, Wang L, Yang CS, Li YF et al. Amine-enriched graphene quantum dots for high-pseudocapacitance supercapacitors. Electrochim Acta 208, 260-266 (2016).

58. Feng RJ, Lei WY, Sui XY, Liu XF, Qi XY et al. Anchoring black phosphorus quantum dots on molybdenum disulfide nanosheets: a $0 \mathrm{D} / 2 \mathrm{D}$ nanohybrid with enhanced visible-and NIR -light photoactivity. Appl Catal B Environ 238, 444-453 (2018).

59. Li GS, Lian ZC, Wang WC, Zhang DQ, Li HX. Nanotube-confinement induced size-controllable $\mathrm{g}-\mathrm{C}_{3} \mathrm{~N}_{4}$ quantum dots modified single-crystalline $\mathrm{TiO}_{2}$ nanotube arrays for stable synergetic photoelectrocatalysis. Nano Energy 19, 446-454 (2016).

60. Wang XW, Sun GZ, Li N, Chen P. Quantum dots derived from two-dimensional materials and their applications for catalysis and energy. Chem Soc Rev 45, 2239-2262 (2016).

61. Xu Q, Ma JF, Khan W, Zeng XB, Li N et al. Highly green fluorescent $\mathrm{Nb}_{2} \mathrm{C}$ MXene quantum dots. Chem Commun $\mathbf{5 6}$, 6648-6651 (2020).

62. Feng YF, Zhou FR, Deng QH, Peng C. Solvothermal synthesis of in situ nitrogen-doped $\mathrm{Ti}_{3} \mathrm{C}_{2} \mathrm{MXene}$ fluorescent quantum dots for selective $\mathrm{Cu}^{2+}$ detection. Ceram Int 46, 8320-8327 (2020).

63. Yu XH, Cai XK, Cui HD, Lee SW, Yu XF et al. Fluorine-free preparation of titanium carbide MXene quantum dots with high near-infrared photothermal performances for cancer therapy. Nanoscale 9, 17859-17864 (2017).

64. Pandey P, Sengupta A, Parmar S, Bansode U, Gosavi S et al. $\mathrm{CsPbBr}{ }_{3}-\mathrm{Ti}_{3} \mathrm{C}_{2} \mathrm{~T}_{\mathrm{x}}$ MXene QD/QD heterojunction: photoluminescence quenching, charge transfer, and $\mathrm{Cd}$ ion sensing application. ACS Appl Nano Mater 3, 3305-3314 (2020).

65. Qin YL, Wang ZQ, Liu NY, Sun Y, Han DX et al. High-yield fabrication of $\mathrm{Ti}_{3} \mathrm{C}_{2} \mathrm{~T}_{x}$ MXene quantum dots and their electrochemiluminescence behavior. Nanoscale 10, $14000-14004$ (2018).

66. Li YJ, Ding L, Guo YC, Liang ZQ, Cui HZ et al. Boosting the photocatalytic ability of $\mathrm{g}-\mathrm{C}_{3} \mathrm{~N}_{4}$ for hydrogen production by $\mathrm{Ti}_{3} \mathrm{C}_{2}$ MXene quantum dots. ACS Appl Mater Interfaces 11, 41440-41447 (2019).

67. Aliofkhazraei M. Handbook of Nanoparticles (Cham, Springer, 2015); http://doi.org/10.1007/978-3-319-15338-4.

68. Cao Y, Wu TT, Zhang K, Meng XD, Dai WH et al. Engineered 
exosome-mediated near-infrared-ii region $\mathrm{V}_{2} \mathrm{C}$ quantum dot delivery for nucleus-target low-temperature photothermal therapy. ACS Nano 13, 1499-1510 (2019).

69. Liang QH, Liu XJ, Zeng GM, Liu ZF, Tang L et al. Surfactantassisted synthesis of photocatalysts: mechanism, synthesis, recent advances and environmental application. Chem Eng $J$ 372, 429-451 (2019).

70. Xu GG, Niu YS, Yang XC, Jin ZY, Wang $Y$ et al. Preparation of $\mathrm{Ti}_{3} \mathrm{C}_{2} \mathrm{~T}_{X}$ mxene-derived quantum dots with white/blue-emitting photoluminescence and electrochemiluminescence. Adv Opt Mater 6, 1800951 (2018).

71. Xu YH, Wang ZT, Guo ZN, Huang H, Xiao QL et al. Solvothermal synthesis and ultrafast photonics of black phosphorus quantum dots. Adv Opt Mater 4, 1223-1229 (2016).

72. Tomita R, Yasu Y, Koike T, Akita M. Combining photoredoxcatalyzed trifluoromethylation and oxidation with DMSO: facile synthesis of a-trifluoromethylated ketones from aromatic alkenes. Angew Chem Int Ed 53, 7144-7148 (2014).

73. Chang MC, Chen SA. Kinetics and mechanism of urethane reactions: phenyl isocyanate-alcohol systems. J Polym Sci Part A Polym Chem 25, 2543-2559 (1987).

74. Zeng ZP, Yan YB, Chen J, Zan P, Tian QH et al. Boosting the photocatalytic ability of $\mathrm{Cu}_{2} \mathrm{O}$ nanowires for $\mathrm{CO}_{2}$ conversion by MXene quantum dots. Adv Funct Mater 29, 1806500 (2019).

75. Zhou L, Wu FM, Yu JH, Deng QH, Zhang FA et al. Titanium carbide $\left(\mathrm{Ti}_{3} \mathrm{C}_{2} \mathrm{~T}_{\mathrm{x}}\right)$ MXene: a novel precursor to amphiphilic carbide-derived graphene quantum dots for fluorescent ink, light-emitting composite and bioimaging. Carbon 118, 50-57 (2017).

76. Xu HX, Zeiger BW, Suslick KS. Sonochemical synthesis of nanomaterials. Chem Soc Rev 42, 2555-2567 (2013).

77. Malaki M, Maleki A, Varma RS. MXenes and ultrasonication. J Mater Chem A 7, 10843-10857 (2019).

78. Bromberger Soquetta M, Schmaltz S, Wesz Righes F, Salvalaggio $R$, de Marsillac Terra $L$. Effects of pretreatment ultrasound bath and ultrasonic probe, in osmotic dehydration, in the kinetics of oven drying and the physicochemical properties of beet snacks. J Food Process Preserv 42, e13393 (2018).

79. Mazzeo R. Editorial. Top Curr Chem 375, 1-36 (2017).

80. Dai WH, Dong HF, Zhang XJ. A semimetal-like molybdenum carbide quantum dots photoacoustic imaging and photothermal agent with high photothermal conversion efficiency. Materials (Basel) 11, 1776 (2018).

81. Zhang TR, Jiang X, Li GC, Yao QF, Lee JY. A red-phosphorous-assisted ball-milling synthesis of few-layered $\mathrm{Ti}_{3} \mathrm{C}_{2} \mathrm{~T}_{x}$ (MXene) nanodot composite. ChemNanoMat 4, 56-60 (2018).

82. Cheng H, Ding LX, Chen GF, Zhang LL, Xue $\mathrm{J}$ et al. Molybdenum carbide nanodots enable efficient electrocatalytic nitrogen fixation under ambient conditions. Adv Mater 30, 1803694 (2018).

83. Wang $\mathrm{YH}$, Li CL, Han XJ, Liu DW, Zhao $\mathrm{HH}$ et al. Ultrasmall $\mathrm{Mo}_{2} \mathrm{C}$ nanoparticle-decorated carbon polyhedrons for enhanced microwave absorption. ACS Appl Nano Mater 1, 5366-5376 (2018).

84. Liu HL, Zhu JC, Lai ZH, Zhao RD, He D. A first-principles study on structural and electronic properties of $\mathrm{Mo}_{2} \mathrm{C}$. Scr Mater $\mathbf{6 0}$, 949-952 (2009).

85. Choi Y, Kang B, Lee J, Kim S, Kim GT et al. Integrative approach toward uncovering the origin of photoluminescence in dual heteroatom-doped carbon nanodots. Chem Mater 28,
6840-6847 (2016).

86. Pan DY, Zhang JC, Li Z, Wu MH. Hydrothermal route for cutting graphene sheets into blue-luminescent graphene quantum dots. Adv Mater 22, 734-738 (2010).

87. Liu S, Tian JQ, Wang L, Zhang YW, Qin XY et al. Hydrothermal treatment of grass: a low-cost, green route to nitrogendoped, carbon-rich, photoluminescent polymer nanodots as an effective fluorescent sensing platform for label-free detection of Cu(II) ions. Adv Mater 24, 2037-2041 (2012).

88. Li XM, Rui MC, Song JZ, Shen ZH, Zeng HB. Carbon and graphene quantum dots for optoelectronic and energy devices: a review. Adv Funct Mater 25, 4929-4947 (2015).

89. Soleymaniha M, Shahbazi MA, Rafieerad AR, Maleki A, Amiri A. Promoting role of mxene nanosheets in biomedical sciences: therapeutic and biosensing innovations. Adv Healthc Mater 8, 1801137 (2019).

90. Sk MA, Ananthanarayanan A, Huang L, Lim KH, Chen P. Revealing the tunable photoluminescence properties of graphene quantum dots. J Mater Chem C 2, 6954-6960 (2014).

91. Bailey RE, Nie S. Alloyed semiconductor quantum dots: tuning the optical properties without changing the particle size. $J$ Am Chem Soc 125, 7100-7106 (2003).

92. Yang $\mathrm{XL}$, Jia QJ, Duan $\mathrm{FH}, \mathrm{Hu} \mathrm{B}$, Wang $\mathrm{MH}$ et al. Multiwall carbon nanotubes loaded with $\mathrm{MoS}_{2}$ quantum dots and MXene quantum dots: non-Pt bifunctional catalyst for the methanol oxidation and oxygen reduction reactions in alkaline solution. Appl Surf Sci 464, 78-87 (2019).

93. Peng JH, Chen XZ, Ong WJ, Zhao XJ, Li N. Surface and heterointerface engineering of $2 \mathrm{D}$ MXenes and their nanocomposites: insights into electro- and photocatalysis. Chem $\mathbf{5}$, 18-50 (2019).

94. Chen X, Sun XK, Xu W, Pan CC, Zhou DL et al. Ratiometric photoluminescence sensing based on $\mathrm{Ti}_{3} \mathrm{C}_{2} \mathrm{MXene}$ quantum dots as an intracellular $\mathrm{pH}$ sensor. Nanoscale 10, 1111-1118 (2018).

95. Liu MW, Zhou J, He Y, Cai ZX, Ge YL et al. $\varepsilon$-Poly-L-lysineprotected $\mathrm{Ti}_{3} \mathrm{C}_{2}$ MXene quantum dots with high quantum yield for fluorometric determination of cytochrome $\mathrm{c}$ and trypsin. Microchim Acta 186, 770 (2019).

96. Puzder A, Williamson AJ, Grossman JC, Galli G. Surface chemistry of silicon nanoclusters. Phys Rev Lett 88, 097401 (2002).

97. Cho IW, Ryu MY. Effect of energy transfer on the optical properties of surface-passivated perovskite films with CdSe/ZnS quantum dots. Sci Rep 9, 18433 (2019).

98. Schubert EF, Kim JK. Solid-state light sources getting smart. Science 308, 1274-1278 (2005).

99. Zhou BZ, Liu MJ, Wen YW, Li Y, Chen R. Atomic layer deposition for quantum dots based devices. Opto-Electronic Adv 3, 190043 (2020).

100. Yang ZW, Gao MY, Wu WJ, Yang XY, Sun XW et al. Recent advances in quantum dot-based light-emitting devices: challenges and possible solutions. Mater Today 24, 69-93 (2019).

101. Rafieerad A, Yan WA, Sequiera GL, Sareen N, Abu - El - Rub $\mathrm{E}$ et al. Application of $\mathrm{Ti}_{3} \mathrm{C}_{2}$ MXene quantum dots for immunomodulation and regenerative medicine. Adv Healthc Mater 8 , 1900569 (2019).

102. Zhu XW, Zhang Z, Xue ZJ, Huang $\mathrm{CH}$, Shan $\mathrm{Y}$ et al. Understanding the selective detection of $\mathrm{Fe}^{3+}$ based on graphene quantum dots as fluorescent probes: the $K_{\mathrm{sp}}$ of a metal 
hydroxide-assisted mechanism. Anal Chem 89, 12054-12058 (2017).

103. Hameed A, Azam A. Sensing capability of fluorescent sodium salt of amoxicillin. Am J Nanomater 1, 27-30 (2013).

104. $\mathrm{Xu} Q, \mathrm{Pu} P$, Zhao JG, Dong CB, Gao $C$ et al. Preparation of highly photoluminescent sulfur-doped carbon dots for $\mathrm{Fe}$ (III) detection. J Mater Chem A 3, 542-546 (2015).

105. Wu P, Li Y, Yan XP. CdTe quantum dots (QDs) based kinetic discrimination of $\mathrm{Fe}^{2+}$ and $\mathrm{Fe}^{3+}$, and $\mathrm{CdTe}$ QDs-fenton hybrid system for sensitive photoluminescent detection of $\mathrm{Fe}^{2+}$. Anal Chem 81, 6252-6257 (2009).

106. Shah $H, X i n ~ Q$, Jia XR, Gong JR. Single precursor-based luminescent nitrogen-doped carbon dots and their application for iron (III) sensing. Arab J Chem 12, 1083-1091 (2019).

107. Dai $X L$, Deng $Y Z$, Peng XG, Jin $Y Z$. Quantum-dot light-emitting diodes for large-area displays: towards the dawn of commercialization. Adv Mater 29, 1607022 (2017).

108. Hoshino A, Hanada, S, Yamamoto K. Toxicity of nanocrystal quantum dots: the relevance of surface modifications. Arch Toxicol 85, 707-720 (2011).

109. Zhang QX, Sun Y, Liu ML, Liu Y. Selective detection of $\mathrm{Fe}^{3+}$ ions based on fluorescence MXene quantum dots via a mechanism integrating electron transfer and inner filter effect. Nanoscale 12, 1826-1832 (2020).

110. Desai ML, Basu H, Singhal RK, Saha S, Kailasa SK. Ultrasmall two dimensional MXene nanosheets for selective and sensitive fluorescence detection of $\mathrm{Ag}^{+}$and $\mathrm{Mn}^{2+}$ ions. Colloids Surf A Physicochem Eng Asp 565, 70-77 (2019).

111. Liang ZC, Kang M, Payne GF, Wang XH, Sun RC. Probing energy and electron transfer mechanisms in fluorescence quenching of biomass carbon quantum dots. ACS Appl Mater Interfaces 8, 17478-17488 (2016).

112. Guo $Z$, Zhu $X H$, Wang SG, Lei $C Y$, Huang $Y$ et al. Fluorescent $\mathrm{Ti}_{3} \mathrm{C}_{2}$ MXene quantum dots for an alkaline phosphatase assay and embryonic stem cell identification based on the inner filter effect. Nanoscale 10, 19579-19585 (2018).

113. Liu MW, He Y, Zhou J, Ge LL, Zhou JG et al. A "naked-eye" colorimetric and ratiometric fluorescence probe for uric acid based on $\mathrm{Ti}_{3} \mathrm{C}_{2}$ MXene quantum dots. Anal Chim Acta 1103, 134-142 (2020).

114. Zhang SL, Liu LW, Ren S, Li ZL, Zhao YH et al. Recent advances in nonlinear optics for bio-imaging applications. OptoElectronic Adv 3, 200003 (2020).

115. Bruchez Jr M, Moronne M, Gin P, Weiss S, Alivisatos AP. Semiconductor nanocrystals as fluorescent biological labels. Science 281, 2013-2016 (1998).

116. Chan WCW, Nie SM. Quantum dot bioconjugates for ultrasensitive nonisotopic detection. Science 281, $2016-2018$ (1998).

117. Yong KT, Law WC, Hu R, Ye L, Liu LW et al. Nanotoxicity assessment of quantum dots: from cellular to primate studies. Chem Soc Rev 42, 1236-1250 (2013).

118. Rasool K, Helal M, Ali A, Ren CE, Gogotsi $Y$ et al. Antibacterial activity of $\mathrm{Ti}_{3} \mathrm{C}_{2} \mathrm{~T}_{x}$ MXene. ACS Nano 10, 3674-3684 (2016).

119. Yang L, Dall'Agnese C, Dall'Agnese $Y$, Chen G, Gao $Y$ et al. Surface-modified metallic $\mathrm{Ti}_{3} \mathrm{C}_{2} \mathrm{~T}_{x}$ mxene as electron transport layer for planar heterojunction perovskite solar cells. Adv Funct Mater 29, 1905694 (2019).

120. Fu HC, Ramalingam V, Kim H, Lin CH, Fang XS et al. MXenecontacted silicon solar cells with $11.5 \%$ efficiency. Adv Energy Mater 9, 1900180 (2019).

\section{Acknowledgements}

This work was supported by National Research Foundation of Korea (2019R1A2C1006586).

\section{Competing interests}

The authors declare no competing financial interests. 